\title{
Ultrasmall manganese ferrites as multimodal bioimaging agents and Fenton/Haber-Weiss catalysts
}

Susana Carregal-Romero, ${ }^{1,2^{*}}$ Ana Beatriz Miguel Coello, ${ }^{1}$ Lydia Martínez-Parra, ${ }^{1}$ Yilian FernándezAfonso, ${ }^{3,4,5}$ Sandra Plaza, ${ }^{1}$ Lucía Gutiérrez, ${ }^{3,4,5}$ Pierre Lecante, ${ }^{6}$ Zuriñe Blasco-Iturri, ${ }^{1}$ Lucía Fadón, ${ }^{1,7}$ Ana C. Almansa-García, ${ }^{1}$ Juliana Carrillo-Romero, ${ }^{1}$ Marco Möller, ${ }^{1}$ Dorleta Otaegui, ${ }^{1}$ Hugo Groult, ${ }^{8}$ Jesús Ruíz-Cabello ${ }^{1,2,9,10^{*}}$

1 Center for Cooperative Research in Biomaterials (CIC biomaGUNE), Basque Research and Technology Alliance (BRTA), Paseo de Miramón 182, 20014 San Sebastián, Spain

2 CIBER de Enfermedades Respiratorias (CIBERES), Madrid, Spain

3 Departamento de Química Analítica, Universidad de Zaragoza, 50009 Zaragoza, Spain

4 Instituto de Nanociencia y Materiales de Aragón (INMA), CSIC-Universidad de Zaragoza, 50009 Zaragoza, Spain

5 Centro de Investigación Biomédica en Red de Bioingeniería, Biomateriales y Nanomedicina (CIBER-BBN), 50009 Zaragoza, Spain

6 CEMES-CNRS, Université de Toulouse, UPR 8011 CNRS, Toulouse, France

7 Center for Cooperative Research in Bioscience (CIC bioGUNE), Building 800, Science and Technology Park of Bizkaia, 48160 Derio, Spain

8 BCBS team (Biotechnologies et Chimie des Bioressources pour la Santé), LIENSs Laboratory (Littoral environment et Sociétés), UMR CNRS 7266, University of La Rochelle, La Rochelle, France

9 Ikerbasque, Basque Foundation for Science, 48013 Bilbao, Spain

${ }^{10}$ Departamento de Química en Ciencias Farmacéuticas, Universidad Complutense de Madrid, 28040 Madrid, Spain

* Correspondence: scarregal@ cicbiomagune.es, jruizcabello@ cicbiomagune.es.

KEYWORDS: magnetic nanoparticles, tailored metal doping, magnetic resonance imaging, positron emission tomography, Fenton/Haber-Weiss catalysis, hydrogen peroxide depletion. 
ABSTRACT: Ultrasmall manganese ferrite nanoparticles display interesting features in bioimaging and Fenton nanocatalysis. However, little is known about how to optimize these nanoparticles to achieve simultaneously the highest efficiency in both types of applications. Herein, we present a cost-efficient synthetic microwave method that enables manganese ferrite nanoparticles to be produced with excellent control in size, chemical composition and colloidal stability. We show how the reaction's $\mathrm{pH}$ has a substantial impact on the Mn incorporation into the nanoparticles and the level of $\mathrm{Mn}$ doping can be finely tailored to a wide range $\left(\mathrm{Mn}_{\mathrm{x}} \mathrm{Fe}_{3-\mathrm{x}} \mathrm{O}_{4}, 0.1 \leq \mathrm{x} \leq 2.4\right)$. The magnetic relaxivities $\left(1.6 \leq \mathrm{r}_{1} \leq 10.6 \mathrm{mM}^{-1} \mathrm{~s}^{-1}\right.$ and $\left(7.5 \leq \mathrm{r}_{2} \leq 29.9 \mathrm{mM}^{-1} \mathrm{~s}^{-1}\right)$ and Fenton/HaberWeiss catalytic properties measured for the differently doped nanoparticles show a strong dependence on the Mn content and, interestingly, on the synthetic reaction's $\mathrm{pH}$. Positive contrast in magnetic resonance imaging is favored by low Mn contents, while dual mode magnetic resonance imaging contrast and catalytic activity increases in nanoparticles with a high degree of Mn doping. We show that this is valid in solution, in a murine model and intracellularly respectively. Besides, this synthetic protocol allows core-radiolabeling for high-sensitive molecular imaging while maintaining relaxometric and catalytic properties. All of these results show the robust characteristics of these multifunctional manganese ferrite nanoparticles as theranostic agents. 


\section{INTRODUCTION}

Manganese ferrite nanoparticles (MFNPs) have garnered increasing interest in the field of nanomedicine as theranostic agents due to their Fenton/Haber-Weiss catalytic properties, their ability to produce contrast on magnetic resonance imaging (MRI) and their capability to produce heat. ${ }^{1-4}$

On the one hand, these nanoparticles (NPs) are capable of consuming hydrogen peroxide intracellularly producing oxygen for catalytic therapy. ${ }^{1,3,5,6}$ They can directly interact with intracellular $\mathrm{H}_{2} \mathrm{O}_{2}$-mediated signaling pathways and balance the concentration of $\mathrm{O}_{2}$ and reactive oxygen species (ROS) known to be related to the pathogenesis of diseases such as cancer, lung fibrosis, or pulmonary hypertension. ${ }^{7-9}$ This brings therapeutic opportunities. For instance, in cancer, manganese ferrites have been used to enhance the therapeutic effect of traditional therapies, such as chemotherapy or photodynamic therapy, thanks to their $\mathrm{H}_{2} \mathrm{O}_{2}$ depletion and $\mathrm{O}_{2}$ generation within the hypoxic and $\mathrm{H}_{2} \mathrm{O}_{2}$-rich microenvironment of the tumor. ${ }^{3,} 10$ Currently, the ROS $/ \mathrm{O}_{2}$ balance is being targeted by many advanced manganese ferrite NP-based therapies that have become a very relevant tool in nanobiotechnology. ${ }^{1,5,10}$

On the other hand, due to their magnetic properties, MFNPs can produce heat after exposure to alternating magnetic fields for hyperthermia and act as $\mathrm{T}_{1}, \mathrm{~T}_{2}$, or dual-mode $\mathrm{T}_{1} / \mathrm{T}_{2}$ contrast agents for MRI. ${ }^{11-13}$ Magnetic hyperthermia is not efficient for ultrasmall MFNPs due to their low specific absorption rate. ${ }^{14}$ However, this size-dependent physicochemical properties can be used strategically to improve MRI contrast. ${ }^{2}$ Indeed, ultrasmall manganese ferrite nanoparticles (UMFNPs) with a size below $5 \mathrm{~nm}$ can show better $\mathrm{T}_{1}$ contrast than their larger MFNPs counterparts while keeping an appropriated transversal relaxivity $r_{2}$ for negative contrast $T_{2} \cdot{ }^{13}, 15$ This allows performing dual contrast imaging $\mathrm{T}_{1} / \mathrm{T}_{2}$ which is sought for reducing imaging artifacts in MRI. ${ }^{16}$ 
Contrary, undoped ultrasmall iron oxide NPs present efficient $\mathrm{T}_{1}$ contrast but reduced $\mathrm{T}_{2}$ contrast and can only be used as positive $\mathrm{T}_{1}$ contrast. ${ }^{15,16}$ Conventional single-mode $\mathrm{T}_{1}$ or $\mathrm{T}_{2}$ imaging can produce misleading results due to image artifacts, particularly in calcified tissues. ${ }^{16}$ Hence, dual contrast $\mathrm{T}_{1} / \mathrm{T}_{2}$ agents based on materials such as doped iron oxides are considered the most promising substitutes of the gold standard Gd chelates. $^{16-18}$

Typically, producing ultrasmall manganese ferrite nanoparticles (UMFNPs) with appropriated dual $\mathrm{T}_{1} / \mathrm{T}_{2}$ contrast have required time-consuming synthetic protocols, organic solvents, high temperatures $\left(\sim 300^{\circ} \mathrm{C}\right)$, and additional purification steps to produce ready-to-use water-soluble nanoparticles. ${ }^{13,18,19}$

In this research work, taking a microwave-assisted fast method that also enables radiolabeling, we demonstrate that it is possible to produce Fenton/Haber-Weiss catalysts based on UMFNPs with dual $\mathrm{T}_{1} / \mathrm{T}_{2}$ MRI contrast. We develop a robust, onepot synthetic protocol that provides UMFNPs with variable $\mathrm{Mn}$ doping $\left(\left(\mathrm{Mn}_{\mathrm{x}} \mathrm{Fe}_{3-\mathrm{x}} \mathrm{O}_{4}\right.\right.$, $0.1 \leq \mathrm{x} \geq 2.4$ ) through a modification of the $\mathrm{Mn} / \mathrm{Fe}$ ratio in the reaction conditions. Interestingly, the synthetic reaction $\mathrm{pH}$ also caused remarkable differences in the $\mathrm{Mn}$ doping level. By tailoring the UMFNPs chemical composition, it was possible to customize magnetic relaxivity values of $r_{1}$ and $r_{2}$ similar to already reported dual-mode $\mathrm{T}_{1} / \mathrm{T}_{2}$ contrast agents. ${ }^{13}$ Modification of the $\mathrm{Mn} / \mathrm{Fe}$ ratio also produces a significant change in the Fenton/Haber-Weiss's catalytic activity of UMFNPs. To our knowledge, there are no comparative studies that correlate catalytic behavior, MRI contrast and UMFNP stoichiometry. This information may benefit the optimization of UMFNPs for practical biomedical applications. 


\section{RESULTS AND DISCUSSION}

Synthesis of water-soluble manganese ferrite with tailored composition. There are four bottom-up methods for preparing ferrites and iron oxide nanoparticles using well-differentiated wet chemistry: hydrolytic (co-precipitation and hydrothermal), organic and polyol. ${ }^{21-23}$ Although organic or polyol methods usually have multiple synthetic steps and are not time and cost-efficient, they are mostly preferred to hydrolytic methods because both co-precipitation and hydrothermal methods have a reputation for providing highly polydisperse NPs. ${ }^{2,11}$ In addition, the NPs obtained have often a low crystallinity. However, recently microwave-assisted hydrolytic methods with controlled pressure and temperature, have demonstrated that it is possible to produce, in one-pot, water-soluble ferrites with well-controlled size and magnetic properties appropriate for bioimaging applications. ${ }^{24-26}$ Because these syntheses can be ultrafast, it is possible to functionalize rapidly the NP surface and modifying the magnetic core with radioisotopes to perform multiple assays, including nuclear imaging with short-lived radioisotopes, ideal for clinical applications. ${ }^{27}$ To demonstrate that microwave-assisted hydrolytic syntheses are optimal methods to produce monodisperse UMFNPs with controlled tailoring of Mn stoichiometry (x, in $\mathrm{Mn}_{\mathrm{x}} \mathrm{Fe}_{3-\mathrm{x}} \mathrm{O}_{4}$ ), we prepared two series of NPs using an increasing ratio from 0.05 to 6 of $[\mathrm{Mn}] /[\mathrm{Fe}]$ precursors. We assayed two different reaction conditions, with and without $\mathrm{HCl}$, in order to study the influence of $\mathrm{pH}$ in our synthesis with respect to the incorporation of $\mathrm{Mn}$. The absence/presence of $\mathrm{HCl}$ in the reaction mixture yielded the following $\mathrm{pH}$ values before and after adding the reducing agent: a) $\mathrm{pH} 4.2 / 10.6$ (protocol $\mathrm{P} 1$ ) and $\mathrm{pH} 2.2 / 9.1$ (protocol P2). The rest of the synthetic conditions, meaning the amount of reducing and coating agent, temperature, and pressure, were similar in all the synthesis and similar to the method we previously developed for iron oxide NPs. ${ }^{26}$ Overall, this led to two series 
of UMFNPs respectively named as follows: i) MnFe1-MnFe7 (protocol P1) and ii) ${ }^{\mathrm{H}+} \mathrm{MnFe} 8{ }_{-}{ }^{\mathrm{H}+} \mathrm{MnFe} 14$ (protocol P2). Figure 1 shows a schematic representation of the synthesis that allows tailoring the UMFNP composition and an example of transmission electron microscopy (TEM) and high-resolution TEM (HRTEM) images of one of the obtained UMFNPs (more images can be found in Figure SI1 and SI3).
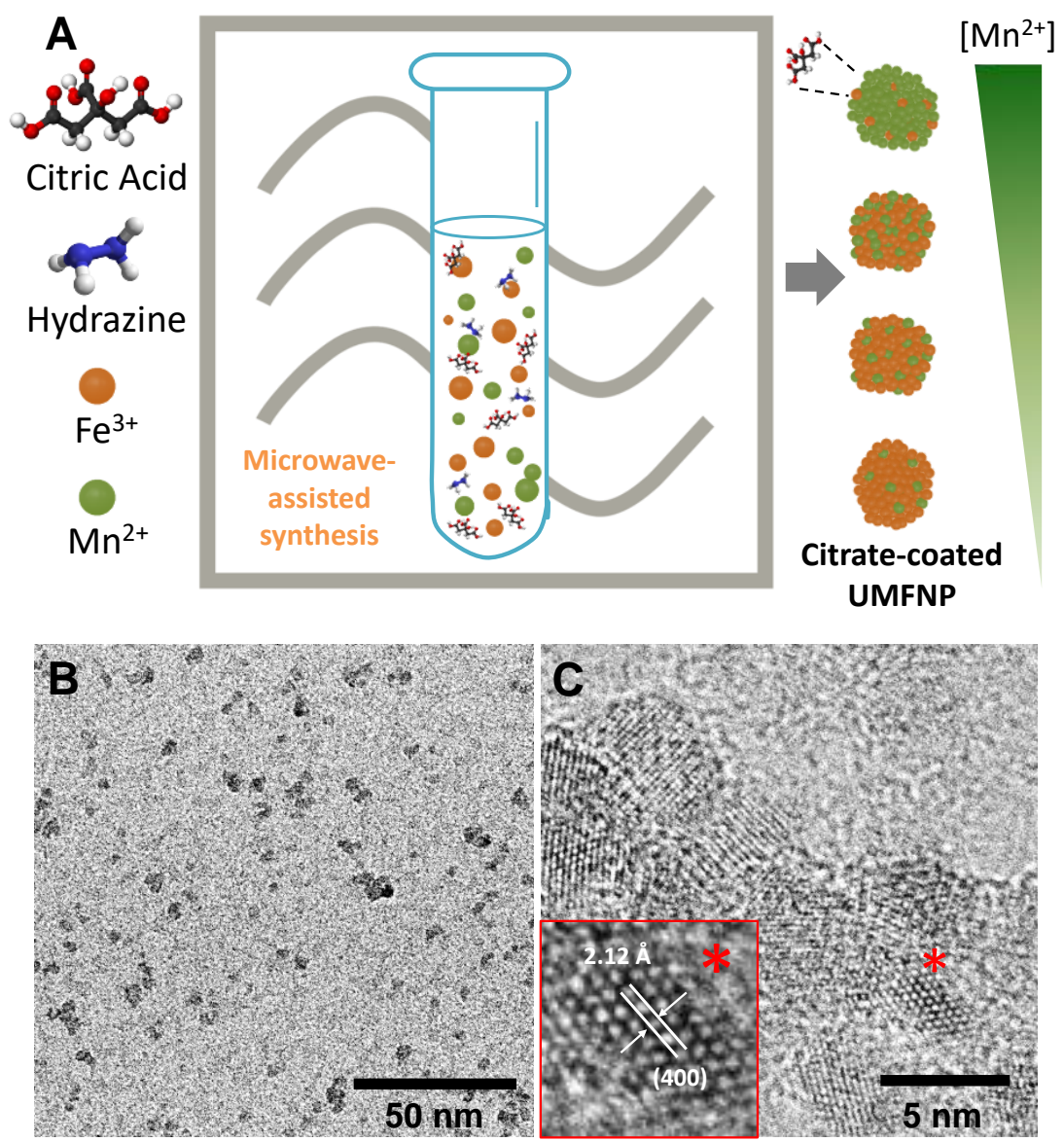

Figure1. A) Schematic representation of the microwave-assisted method used to produce citrate-coated UMFNPs with fine control in the chemical composition. B) TEM and C) HRTEM images of citrate-coated $\mathrm{Mn}_{0.63} \mathrm{Fe}_{2.38} \mathrm{O}_{4}(\mathrm{MnFe} 4)$ produced in the onepot microwave-assisted synthesis. The inset shows the lattice fringes of the selected NP $\left.{ }^{*}\right)$ with a bottom side of $3.8 \mathrm{~nm}$. 
Table 1. Synthetic parameters and physicochemical characterization of the UMFNPs: theoretical and measured $\mathrm{Mn}$ stoichiometries ( $\mathrm{x}$ theoretical and measured), average diameters measured from TEM images, average hydrodynamic diameters measured with DLS and the corresponding zeta potential ( $\zeta$-pot). The standard deviations are obtained comparing the values obtained from different sample batches.

\begin{tabular}{|c|c|c|c|c|c|c|c|}
\hline Sample & Abbr. & {$[\mathrm{Mn}] /[\mathrm{Fe}]_{(\mathbf{i})}$} & $\begin{array}{c}\mathbf{X} \\
\text { theoretical }\end{array}$ & $\begin{array}{c}\mathbf{X} \\
\text { measured }\end{array}$ & $\begin{array}{l}\mathbf{d}_{\text {TEM }} \\
(\mathrm{nm})\end{array}$ & $\begin{array}{c}\mathbf{d}_{\mathbf{h}} \\
(\mathrm{nm})\end{array}$ & $\begin{array}{l}\zeta \text {-pot } \\
(\mathrm{mV})\end{array}$ \\
\hline $\mathrm{Mn}_{0.15} \mathrm{Fe}_{2.85} \mathrm{O}_{4}$ & $\mathrm{MnFe} 1$ & 0.12 & 0.32 & $0.15 \pm 0.01$ & $3.5 \pm 0.1$ & $16.1 \pm 0.9$ & -14.4 \\
\hline $\mathrm{Mn}_{0.30} \mathrm{Fe}_{2.70} \mathrm{O}_{4}$ & $\mathrm{MnFe} 2$ & 0.34 & 0.75 & $0.30 \pm 0.03$ & $4.3 \pm 0.2$ & $25.8 \pm 1.6$ & -18.7 \\
\hline $\mathrm{Mn}_{0.50} \mathrm{Fe}_{2.50} \mathrm{O}_{4}$ & $\mathrm{MnFe} 3$ & 0.68 & 1.23 & $0.50 \pm 0.03$ & $3.8 \pm 0.4$ & $30.2 \pm 1.8$ & -23.7 \\
\hline $\mathrm{Mn}_{0.62} \mathrm{Fe}_{2.38} \mathrm{O}_{4}$ & $\mathrm{MnFe} 4$ & 1.09 & 1.57 & $0.62 \pm 0.02$ & $4.0 \pm 0.1$ & $19.5 \pm 1.3$ & -20.7 \\
\hline $\mathrm{Mn}_{1.01} \mathrm{Fe}_{1.99} \mathrm{O}_{4}$ & $\mathrm{MnFe} 5$ & 2.50 & 2.14 & $1.01 \pm 0.04$ & $4.0 \pm 0.3$ & $24.2 \pm 1.7$ & -24.3 \\
\hline $\mathrm{Mn}_{1.15} \mathrm{Fe}_{1.85} \mathrm{O}_{4}$ & MnFe6 & 3.72 & 2.35 & $1.15 \pm 0.16$ & $4.1 \pm 0.7$ & $16.5 \pm 1.8$ & -25.1 \\
\hline $\mathrm{Mn}_{1.37} \mathrm{Fe}_{1.63} \mathrm{O}_{4}$ & MnFe7 & 5.97 & 2.57 & $1.37 \pm 0.14$ & $4.1 \pm 0.9$ & $16.6 \pm 0.5$ & -19.3 \\
\hline $\mathrm{Mn}_{0.14} \mathrm{Fe}_{2.86} \mathrm{O}_{4}$ & ${ }^{\mathrm{H}+} \mathrm{MnFe} 8$ & 0.05 & 0.15 & $0.14 \pm 0.004$ & $3.8 \pm 0.3$ & $13.5 \pm 0.9$ & -22.6 \\
\hline $\mathrm{Mn}_{0.35} \mathrm{Fe}_{2.65} \mathrm{O}_{4}$ & ${ }^{\mathrm{H}+} \mathrm{MnFe} 9$ & 0.12 & 0.32 & $0.35 \pm 0.04$ & $3.6 \pm 0.2$ & $14.7 \pm 3.9$ & -27.5 \\
\hline $\mathrm{Mn}_{0.51} \mathrm{Fe}_{2.49} \mathrm{O}_{4}$ & ${ }^{\mathrm{H}+} \mathrm{MnFe} 10$ & 0.20 & 0.50 & $0.51 \pm 0.02$ & $3.8 \pm 0.9$ & $15.2 \pm 2.2$ & -21.1 \\
\hline $\mathrm{Mn}_{0.95} \mathrm{Fe}_{2.05} \mathrm{O}_{4}$ & ${ }^{\mathrm{H}+} \mathrm{MnFe} 11$ & 0.51 & 1.00 & $0.95 \pm 0.05$ & $4.2 \pm 0.8$ & $13.4 \pm 0.1$ & -21.1 \\
\hline $\mathrm{Mn}_{1.38} \mathrm{Fe}_{1.62} \mathrm{O}_{4}$ & ${ }^{\mathrm{H}+} \mathrm{MnFe} 12$ & 1.09 & 1.50 & $1.38 \pm 0.04$ & $3.3 \pm 0.8$ & $13.3 \pm 1.4$ & -14.9 \\
\hline $\mathrm{Mn}_{1.83} \mathrm{Fe}_{1.17} \mathrm{O}_{4}$ & ${ }^{\mathrm{H}+} \mathrm{MnFe} 13$ & 1.99 & 2.00 & $1.83 \pm 0.22$ & $3.9 \pm 0.5$ & $14.1 \pm 0.5$ & -14.7 \\
\hline $\mathrm{Mn}_{2.42} \mathrm{Fe}_{0.58} \mathrm{O}_{4}$ & ${ }^{\mathrm{H}+} \mathrm{MnFe} 14$ & 6.02 & 2.57 & $2.42 \pm 0.04$ & $3.7 \pm 0.7$ & $16.9 \pm 4.6$ & -22.3 \\
\hline
\end{tabular}

* SD of the mean of $\mathrm{n}$ independent syntheses. (i) initial concentration ratio. MnFe1-MnFe7 (black letters) have been produced with protocol $\mathrm{P} 1$ and $\mathrm{MnFe} 8-\mathrm{MnFe} 14$ (grey letters) have been produced with protocol P2.

Table 1 gathers the chemical formula $\mathrm{Mn}_{\mathrm{x}} \mathrm{Fe}_{3-\mathrm{x}} \mathrm{O}_{4}$ determined from inductively coupled plasma mass spectrometry (ICP-MS) and the characterization obtained for all the UMFNPs, synthetized with the two different protocols at increasing reaction ratios $[\mathrm{Mn}] /[\mathrm{Fe}]$, with TEM and dynamic light scattering (DLS) analysis. To further investigate the stoichiometry of UMFNPs, we performed elemental analysis. All UMFNPs analyzed with X-ray photoelectron spectroscopy (XPS) confirmed the presence of $\mathrm{O}, \mathrm{Mn}, \mathrm{Fe}$ and $\mathrm{C}$, the main components of the citrate-coated UMFNPs, and the intensity decrease of $\mathrm{Fe} 2 \mathrm{p}$ peak while enhancing the Mn $2 \mathrm{p}$ peak intensity for UMFNPs with increasing Mn stoichiometry (Figure SI5-7). Table 1 and Figure 2A indicates a relative homogeneity of the UMFNP average core size obtained with TEM 
(there are no statistical significant differences) regardless the incorporation of $\mathrm{Mn}$. The mean core size of UMFNPs are negligible affected by the presence of $\mathrm{HCl}$, while the hydrodynamic size and size distribution were significantly affected by the acid conditions. UMFNPs obtained with P1 were larger (Table 1) and more polydispersed (Figure SI2) than the ones obtained with $\mathrm{P} 2$. On the other hand, $\mathrm{pH}$ dramatically influences the $\mathrm{Mn}$ incorporation. Figure $2 \mathrm{C}$ compares the obtained $\mathrm{x}_{\text {measured }}$ values with the theoretical Mn stoichiometry value $\mathrm{x}_{\text {theoretical }}$ considering a reaction yield of $100 \%$ for similar precursor ratios of $[\mathrm{Mn}] /[\mathrm{Fe}]$. It shows a much greater effective incorporation of $\mathrm{Mn}$ in the ferrites produced with $\mathrm{P} 2$ than those produced with $\mathrm{P} 1$. Interestingly, we found that acidic conditions achieves a Mn yield higher than $50 \%$ regardless the Mn stoichiometry (Figures 2D and SI2). Contrarywise, the absence of acid drives to significantly lower $\mathrm{Mn}$ yields at higher $\mathrm{x}_{\text {measured }}$, indicating the low efficiency of P1 synthetic protocol. However, it is not clear how the $\mathrm{HCl}$ presence at a concentration of $[\mathrm{HCl}]=0.02 \mathrm{M}$ can affect the incorporation of $\mathrm{Mn}$. 

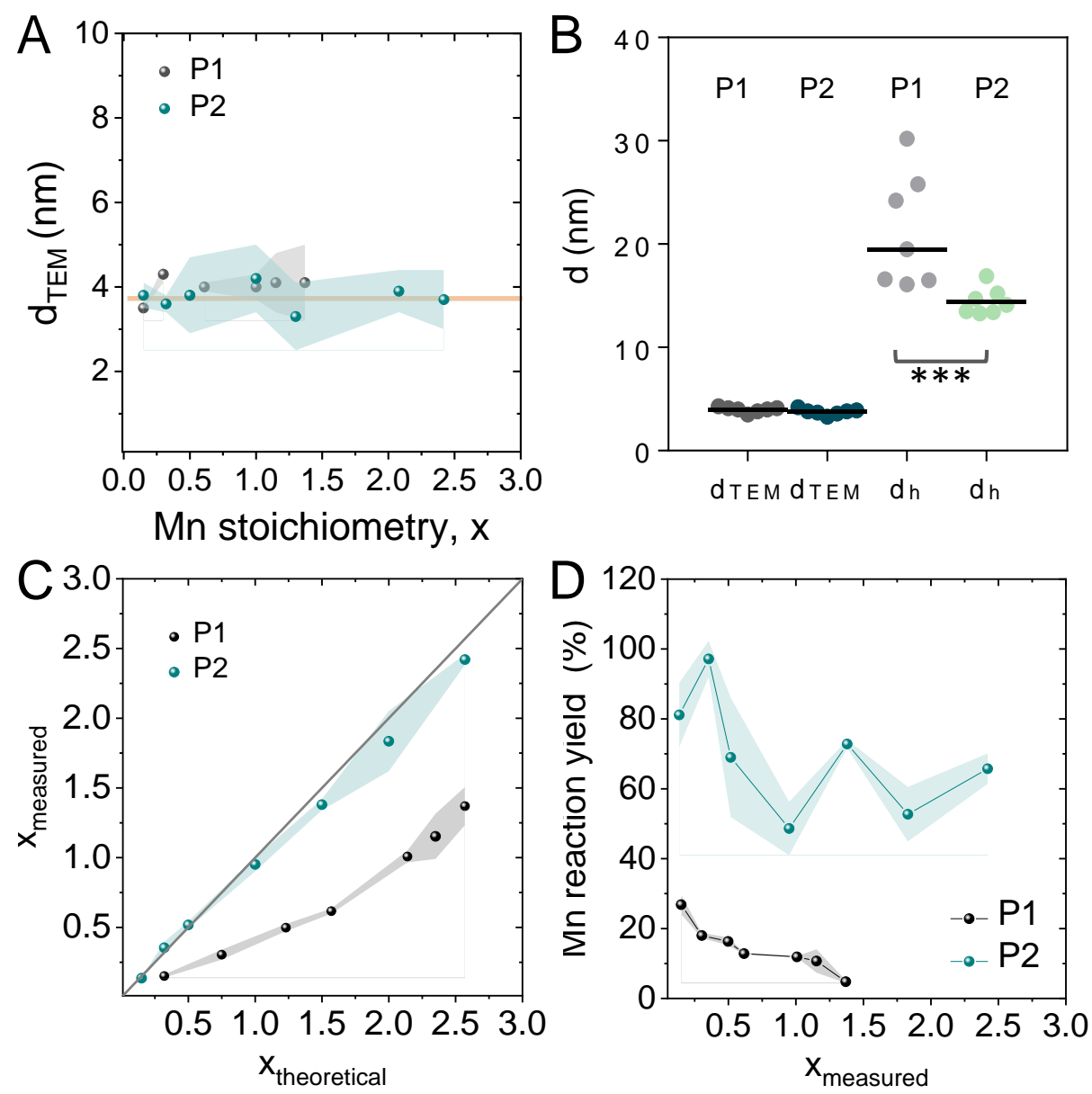

Figure 2. (A) Core diameter of UMFNPs with different Mn stoichiometry x produced with protocols P1 and P2. The orange line represents the average size of all prepared UMFNPs $(3.9 \mathrm{~nm})$. (B) Core and hydrodynamic diameter differences between the synthetic protocols determined by TEM $\left(\mathrm{d}_{\mathrm{TEM}}\right)$ and DLS $\left(\mathrm{d}_{\mathrm{h}}\right)$. (C) Theoretical Mn stoichiometry x (gray line) considering a reaction conversion of $100 \%$ of precursor's initial concentration compared to $\mathrm{x}$, measured by ICP-MS for the P1 and P2 synthetic protocols. (D) Mn incorporation yield in UMFNPs produced with two synthetic protocols $\mathrm{P} 1$ and $\mathrm{P} 2$.

As far as we know, the increase of $\mathrm{pH}$ has only been reported to increase the size of iron oxide NPs, rather than influencing their transition metals doping level. ${ }^{28}$ In our protocol is clear that $\mathrm{pH}$ might be influencing the formation mechanism of UMFNPs 
due to the different chemical compositions obtained with similar precursor ratios $[\mathrm{Mn}] /[\mathrm{Fe}]$. In ferrites doped with $\mathrm{Zn}^{2+}$, Szczerba et al. suggested that this type of disparities in metal doping arise from differences in the sub nano/atomic structure. ${ }^{29}$ They determined, for inverse spinel structures, that slightly different synthetic protocols allow the metal dopant to occupy both the octahedral $\mathrm{O}_{\mathrm{h}}$ and tetrahedral $\mathrm{T}_{\mathrm{d}}$ positions, while other protocols only allow the divalent metal cation to be in $T_{d}$ positions. In that case, these distinct doping levels were associated with differences in the NP nucleation and growth mechanism of doped ferrites, but the key parameters that made it possible remain elusive. In our synthetic method, hydrazine is added in one-pot to an aqueous solution of citric acid, $\mathrm{FeCl}_{3}$ and $\mathrm{MnCl}_{2}$. In this first step, hydrazine $\mathrm{N}_{2} \mathrm{H}_{4}$ rapidly hydrolyzes to hydrazinium $\left(\mathrm{N}_{2} \mathrm{H}_{5}\right)^{+}\left(\right.$and $\left.\mathrm{OH}^{-}\right)$which reduces $\mathrm{Fe}^{3+}$ to $\mathrm{Fe}^{2+} \cdot{ }^{28}$ The $\mathrm{Mn}^{2+}$ and $\mathrm{Fe}^{2+}$ ions then react with dissolved oxygen and hydroxyl ions to form intermediate metal oxides that condense and turn into more stable and definitive spinel structures. ${ }^{28}$, ${ }^{30}$ The addition of $\mathrm{HCl}$ in $\mathrm{P} 2$ can affect in three directions: decreasing the reducing capacity of hydrazine, limiting the $\mathrm{OH}^{-}$concentration and forming iron complexes such as $\left[\mathrm{Fe}\left(\mathrm{OH}_{2}\right)_{5} \mathrm{Cl}\right]^{2+} \cdot{ }^{31-33}$ However, a detailed study on the reaction mechanism would be required beyond this work to determine the key parameters that rule the $\mathrm{Mn}$ incorporation in UMFNPs. 

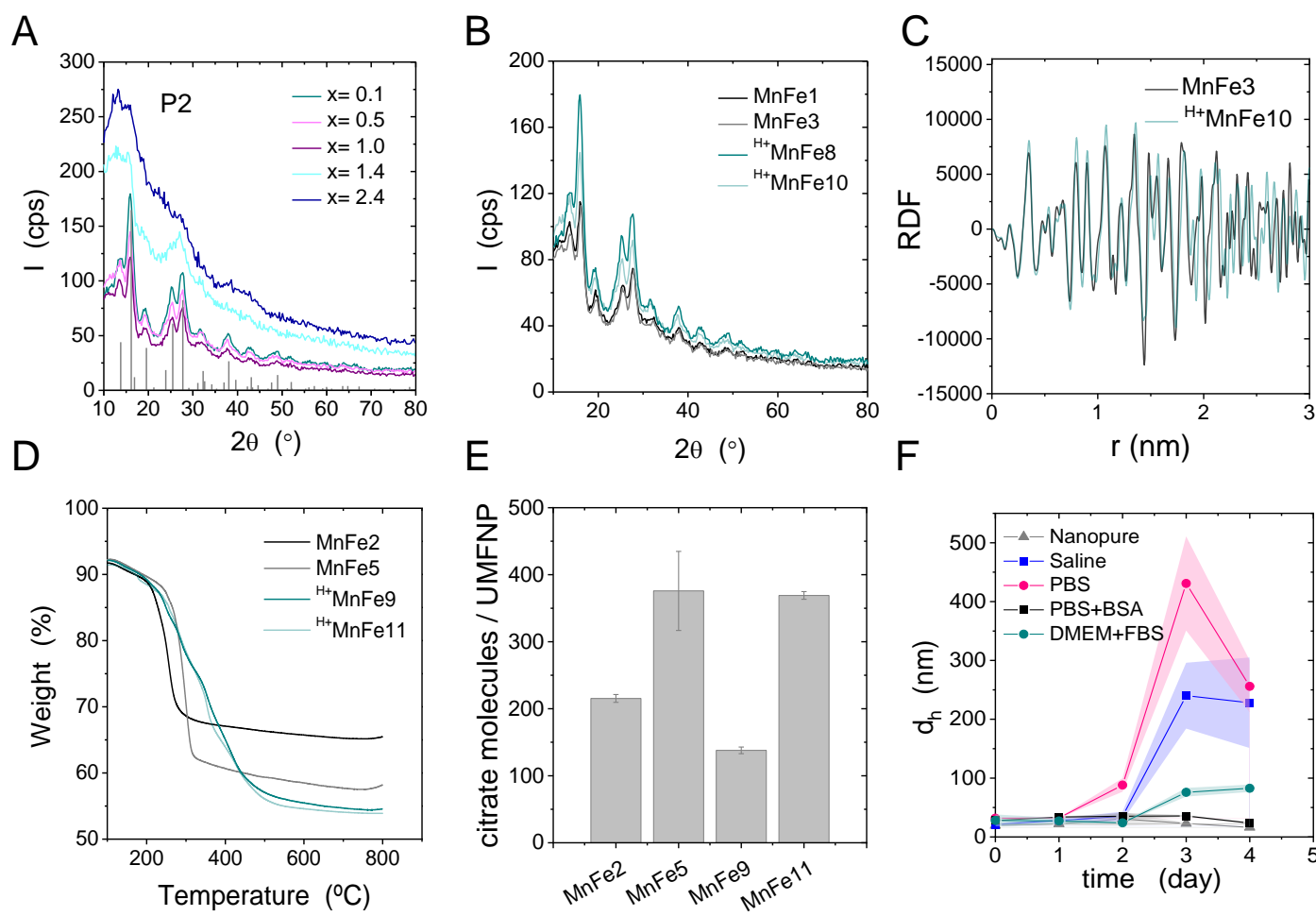

$\mathrm{F}$

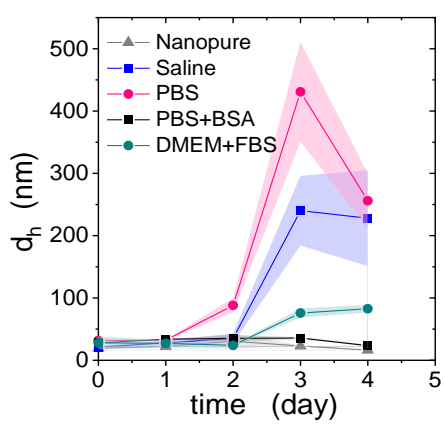

Figure 3. (A) WAXS profile for P2_UMFNPs series as compared with magnetite (grey peaks). (B) Comparison of WAXS profile for UMFNPs prepared with P1 (MnFe1-3) and $\mathrm{P} 2\left({ }^{\mathrm{H}+} \mathrm{MnFe} 8-10\right)$ and similar $\mathrm{x}$ value (0.1 and 0.5 , respectively). (C) RDF analysis of the MnFe3 (black line, $\mathrm{x}=0.50$ ) and ${ }^{\mathrm{H}+} \mathrm{MnFe} 10$ (green line, $\mathrm{x}=0.51$ ). (D) TGA combustion curves of UMFNPs obtained with $\mathrm{P} 1$ or $\mathrm{P} 2$ and with $\mathrm{x} \sim 0.3(\mathrm{MnFe} 2$ and $\left.{ }^{\mathrm{H}+} \mathrm{MnFe} 9\right)$ and $\mathrm{x} \sim 1 \quad\left(\mathrm{MnFe} 5\right.$ and $\left.{ }^{\mathrm{H}+} \mathrm{MnFe} 11\right)$. (E) Calculated number of citrate molecules per UMFNP: MnFe2 (x=0.30), MnFe $5(x=1.01),{ }^{\mathrm{H}+} \mathrm{MnFe} 9(\mathrm{x}=0.32)$ and ${ }^{\mathrm{H}+} \mathrm{MnFe} 11$ (x=0.95). (F) Colloidal stability of UMFNPs (this plot corresponds to MnFe6) at different time points in different solutions: $(\Delta)$ water, ( $\square)$ saline $(0.9 \%$ $\mathrm{NaCl}),(\bullet) \mathrm{PBS}$ at $\mathrm{pH} 7.4$, ( $\bullet$ PBS supplemented with BSA $(800 \mu \mathrm{M})$, and ( $\square)$ cell culture media DMEM supplemented with $10 \%$ FBS and $1 \%$ of penicillin and streptomycin.

The crystallinity of UMFNPs obtained with P1, and P2 syntheses were studied with both HRTEM and wide-angle x-ray scattering (WAXS). We observed with HRTEM 
clear lattice fringes, as shown in Figure 1C and SI3. The observed lattice spacings of 2.12 $\AA 2.45 \AA, 2.56 \AA$ and $3.01 \AA$ could correspond to the (400), (222), (311) and (220) of the lattice planes that would be in good agreement with the inverse spinel structure of standard manganese ferrite nanocrystals. ${ }^{2}, 34$ However, due to the small size of nanoparticles, WAXS analysis was more accurate to determine the crystallinity/amorphization of the UMFNPs series. Figure 3A shows the WAXS profile for the P2 UMFNP series compared with the reported scattering pattern of magnetite. Visibly the crystalline structure sticks to the inverse spinel structure of $\mathrm{Fe}_{3} \mathrm{O}_{4}$, with no significant change in crystalline parameters for low Mn stoichiometries, $\mathrm{x}<1.4$. Contrary, nearly full amorphization was obtained for the UMFNPs with $\mathrm{x} \geq 1.4$. Interestingly, when comparing P1 and P2 UMFNPs, a higher degree of crystallinity was observed for P2 UMFNPs (Figure 3B). However, for both kinds of UMFNPs, the corresponding radial distribution function (RDF) analysis, shown in Figure 3C, determined similar crystalline domain size steadily close to $3 \mathrm{~nm}$ and a drop in amplitude between ${ }^{\mathrm{H}+} \mathrm{MnFe} 10$ and $\mathrm{MnFe} 3$ consistent with the decrease of crystallinity between P1 and P2 NPs.

We next looked at the effect of the synthetic conditions on the citrate coating of UMFNPs. We performed thermogravimetric (TGA) analysis (Figure 3D and E) which provides key information about the physicochemical properties of UMFNPs for biomedical applications. The obtained combustion profiles were similar to other reported citrate-coated NPs. Their loss of mass corresponding to a thick citrate coating was between 30 to $40 \%$ up to $600{ }^{\circ} \mathrm{C} .{ }^{26}$ Interestingly, when comparing the number of citrate molecules per NP, the obtained results determined that UMFNPs (both in P1 and P2) with higher Mn stoichiometry contained higher amounts of citrate molecules on their surface (Figure 3E). This thickening of the coating shell for higher doping degrees 
was already observed for $\mathrm{Cu}$ doped ferrites and could affect the magnetic and relaxometric properties of UMFNPs. ${ }^{35}$ In addition, TGA results also confirmed that P1 UMFNPs have a thicker citrate coating than P2 as DLS measurements indicated in Figure 2B.

Finally, a key aspect for any application of UMFNPs is their colloidal stability, as due to their size they are typically metastable (due to short-range van der Waals attraction) and can lead to undesirable agglomeration of $\mathrm{NP}^{26}$ To avoid agglomeration, a coating agent can introduce steric or electrostatic repulsion to stabilize the NPs. In order to decipher the stability of the citrate-coated UMFPNs, we have followed the stability in terms of hydrodynamic size (Figure 3F) of these UMFNPs during several days at $37^{\circ} \mathrm{C}$ in a variety of buffers and solvents often used as cell culture media or for in vivo NP administration: a) nanopure water, b) saline solution $(0.9 \% \mathrm{NaCl})$, c) PBS buffer, $\mathrm{pH} 7.4,5 \mathrm{mM}$, d) bovine serum albumin (BSA) $800 \mu \mathrm{M}$ dissolved in PBS buffer, $\mathrm{pH} 7.4,5 \mathrm{mM}$ and d) cell culture media Dulbecco's modified eagle's medium (DMEM) supplemented with $10 \%$ fetal bovine serum (FBS) and $1 \%$ penicillin and streptomycin. ${ }^{36}$. Note that in the protein containing media it was possible to separate the scattering of the proteins and the UMFNPs as the size of UMFNPs was sufficiently larger than the protein size. The results are presented in Figure 3F. UMFNPs were stable up to $24 \mathrm{~h}$ in all buffers. However, the presence of salts and $\mathrm{pH} 7.4$ induced agglomeration when the incubation times where $t>1-2$ days. In nanopure water, UMFNPs were stable for 5 days. The presence of proteins in the media (BSA or FBS) stabilized the NPs in complex media such as DMEM, as has been reported for citratecoated Au NPs. ${ }^{37}$ Colloidal stability was studied for both P1 and P2 UMFNPs obtaining similar results (Figure SI7). We also freeze-dried the UMFNPs and demonstrated colloidal stability after redispersion in water solutions ensuring their long self-life 
(Figure SI7)). ${ }^{38}$ In conclusion, the prepared UMFNPs have relatively high colloidal stability and it could be assumed that intravenous administration might not trigger NP agglomeration, at least to a large extent. ${ }^{36}$

Therefore, our microwave-assisted synthesis method allowed producing colloidally stable UMFNPs. The Mn incorporation yield, the NP crystallinity and the coating thickness could be modulated by modifying the reaction ratio $[\mathrm{Mn}] /[\mathrm{Fe}]$ and $\mathrm{pH}$, obtaining a library of UMFNPs with tailored physicochemical properties.

Magnetic characterization of UMFNPs. Field dependent magnetization, $M(H)$, hysteresis curves were recorded at $300 \mathrm{~K}$. All UMFNPs showed a superparamagnetic behavior with very small remnant magnetization and coercive field values (Figure 4) at this temperature. Saturation magnetization $\left(\mathrm{M}_{\mathrm{s}}\right)$ values from all the NPs characterized were in the range between 1 and $45 \mathrm{Am}^{2} / \mathrm{kg}$ of ferrite. These values, are lower than those of other manganese ferrites reported in the literature for bigger particles (particle diameter $\approx 8 \mathrm{~nm}, \mathrm{M}_{\mathrm{s}}$ between 60 and $\left.75 \mathrm{Am}^{2} / \mathrm{kg}\right){ }^{19}$ However, we have previously described that undoped iron oxide NPs of similar sizes $(\approx 4 \mathrm{~nm})$ and coating, as the ones reported here, usually present $\mathrm{M}_{\mathrm{s}}$ values (down to $20 \mathrm{Am}^{2} / \mathrm{kg}$ ) ${ }^{26}$ below the typical values for bulk magnetite or maghemite (92-100 or $60-80 \mathrm{Am}^{2} / \mathrm{kg}$ respectively). ${ }^{39}$ Thus, the low $\mathrm{M}_{\mathrm{s}}$ values reported for these UMFNPs could be explained, in part, due to the small particle sizes obtained by this synthetic approach. Nevertheless, although with slight deviations, the general tendency for both synthetic protocols was that $M_{s}$ values decreased with increasing levels of Mn doping (x) (Figure 4).

Previous works studying the saturation magnetization values of manganese ferrite NPs had reported this same trend of decreasing $M_{s}$ values for increasing levels of $M n$ doping up to molar ratios of $\approx 0.2(\mathrm{Mn} / \mathrm{Fe})$, that corresponds to $\mathrm{x} \approx 0.5 .^{11,19,40} \mathrm{~A}$ 
tendency of obtaining increasing $\mathrm{M}_{\mathrm{s}}$ values from 0.2 molar ration onwards was described in some of these previous results, although the maximum Mn stoichiometry only reached $\approx 0.45 \mathrm{Mn} / \mathrm{Fe}$ molar ratio, much lower than the around 4 molar ratio obtained here for the sample with the highest amount of incorporated $\mathrm{Mn}\left({ }^{\mathrm{H}+} \mathrm{MnFe} 14, \mathrm{x}\right.$ $=2.4$, Molar ratio $\approx 4)$. In our case, we do not observe this "V" behaviour on the $\mathrm{M}(\mathrm{H})$ vs $x$ results, and, in contrast, a decrease of the $M_{s}$ values with the $M n$ doping is observed for all the range of studied $\mathrm{x}$ values.

Interestingly, one of the samples, ${ }^{\mathrm{H}+} \mathrm{MnFe} 14$, the one with the highest amount of $\mathrm{Mn}$ presented a paramagnetic contribution observed in the $\mathrm{M}(\mathrm{H})$ curves at the highest fields. To verify this contribution, the temperature dependence of the AC magnetic susceptibility was measured for selected samples (Figure 4D). All the samples presented the typical magnetic relaxation phenomenon of magnetic nanoparticles, with a maximum in the in-phase susceptibility ( $\left.\chi^{\prime}\right)$ accompanied by a maximum at slightly lower temperatures for the out-of-phase susceptibility ( $\chi$ '). Sample ${ }^{\mathrm{H}+} \mathrm{MnFe} 14$ also presented a paramagnetic contribution, observed at low temperatures in the $\chi^{\prime}(\mathrm{T})$ data. One of the possibilities to explain this paramagnetic contribution could be the formation of manganese oxide during the synthesis. The XPS elemental analysis of the Mn $2 p$ core level shows a satellite peak that it is compatible with $\mathrm{MnO}$ (Figures SI5-7). Another, more remote, possibility could be the possible cation leaching that has been recently described during water transfer protocols. ${ }^{19}$ However, this paramagnetic contribution has not been observed in any of the other characterized samples, so probably the formation of paramagnetic manganese oxide as a result of the highest Mn concentration used during the synthesis is a more plausible explanation of this paramagnetic signal. 

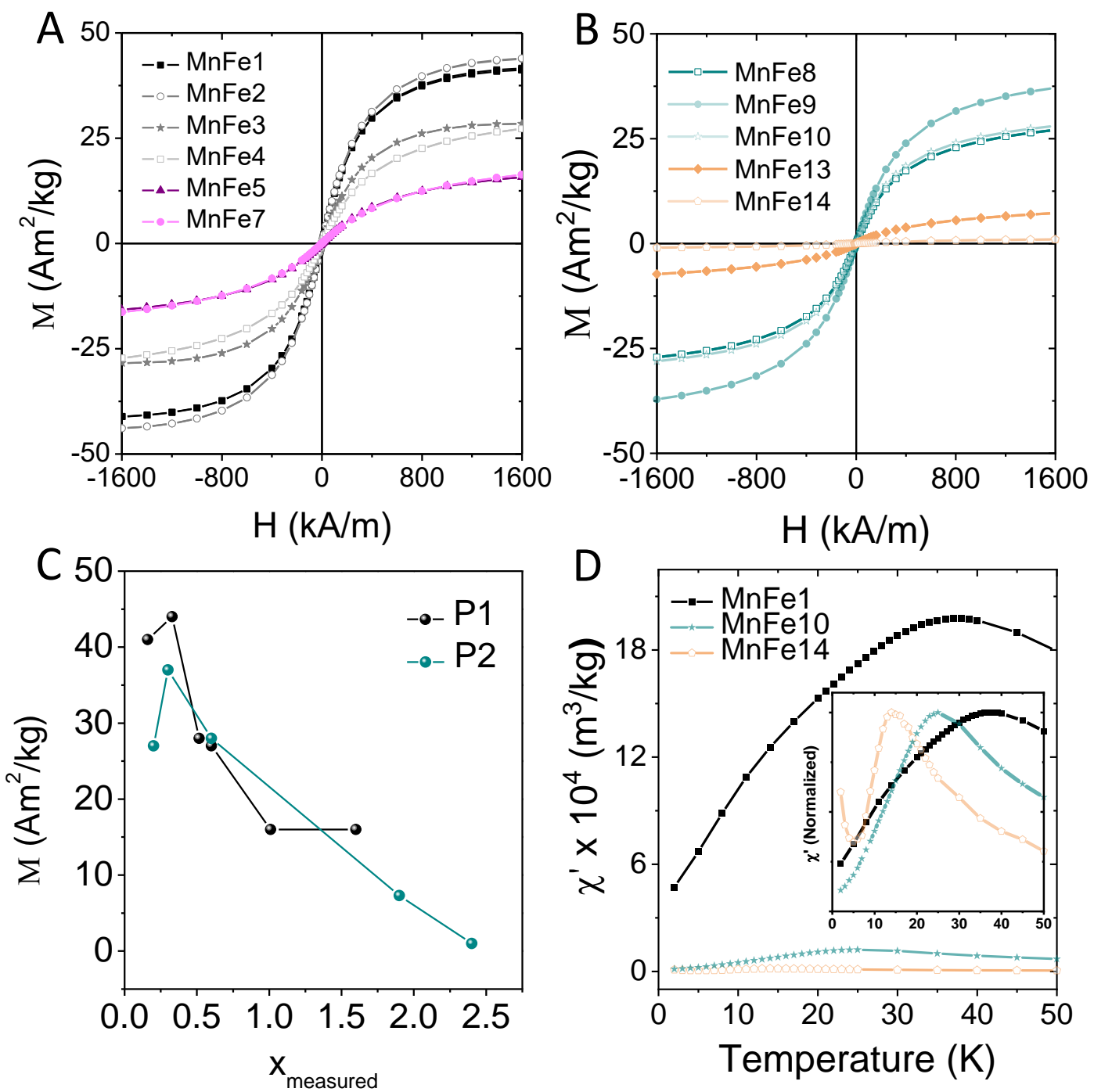

Figure 4. Magnetic characterization results. (A) and (B) Field dependent magnetization of UMFNPs obtained from synthetic protocolos P1 and P2 respectively. (C) Saturation magnetization values as a function of the Mn doping (x). (D) Temperature dependence of the in-phase magnetic susceptibility of selected samples. In the inset, data had been scaled to their maxima to allow a better comparison of the position in temperature and the presence of a paramagnetic contribution easily observed for $\mathrm{MnFe} 14$ at low temperature.

The location in temperature of the susceptibility maxima (both in-phase, $\chi$, and outof-phase, $\chi$ ") follows a trend that is related to the Mn stoichiometry, with samples with the highest amount of $\mathrm{Mn}$ presenting their corresponding maxima at the lowest 
temperatures. The location in temperature of the susceptibility maxima depends on the chemical composition and the particle volume ${ }^{41}$ but also on the degree of dipolar interactions among the particles. ${ }^{42}$ Although effects from the dipolar interactions cannot be discarded, in this case, given that all the UMFNPs present very similar particle size distributions and not so different hydrodynamic sizes, it seems reasonable to correlate these differences in the $\chi(T)$ location with the chemical composition of the UMFNPs. One example is plotted in Figure 4D, where MnFe1 and ${ }^{\mathrm{H}+} \mathrm{MnFe} 14$, both with very similar size distribution and hydrodynamic properties present very different location of their $\chi^{\prime}(\mathrm{T})$ maxima given the big differences in Mn stoichiometry. These results agree with those previously reported for manganese ferrites. ${ }^{19}$

Finally, the height of the $\chi^{\prime}(\mathrm{T})$ maxima per mass of sample also follows a trend associated to the Mn stoichiometry, being the UMFNPs containing more Mn those that present lower maxima per mass of sample, associated to lower particle magnetic moments, a parameter that has a direct impact on their relaxometric properties. ${ }^{43}$

\section{Programming $T_{1} / T_{2}$ contrast efficiency by tailoring Mn stoichiometry. To} evaluate the feasibility of the UMFNPs as efficient $T_{1}\left(1<r_{2} / r_{1}<3\right), T_{2}\left(r_{2} / r_{1}>10\right)$ or dualmode $\mathrm{T}_{1} / \mathrm{T}_{2}\left(3<\mathrm{r}_{2} / \mathrm{r}_{1}<10\right)$ MRI-based contrast agents, their relaxometric properties were measured with a $1.5 \mathrm{~T}$ relaxometer (Figure 5A) and a $7 \mathrm{~T}$ pre-clinical MRI scanner. First, we observed (Figure 5B-C) the impact of the presence of Mn within the ferrite as compared with undoped iron oxide NPs (IONP) produced with similar synthesis. ${ }^{26}$ Both the $T_{1}$ and $T_{2}$ contrast ability improved with a slight Mn doping $(x \leq 0.15)$ as compared with IONP $(x=0)$, from $r_{1}=6.8$ and $r_{2}=15.9 \mathrm{mM}^{-1} \mathrm{~s}^{-1}$ for IONP to $r_{1}=8.8 \pm 0.7, r_{2}=22.8$ $\pm 1.7 \mathrm{mM}^{-1} \mathrm{~s}^{-1}$ for MnFe1 $(\mathrm{x}=0.15, \mathrm{P} 1)$ and $\mathrm{r}_{1}=10.4 \pm 1.7, \mathrm{r}_{2}=24.8 \pm 3.9 \mathrm{mM}^{-1} \mathrm{~s}^{-1}$ for

${ }^{\mathrm{H}+} \mathrm{MnFe} 8(\mathrm{x}=0.14, \mathrm{P} 2)$. This enhancement in the $\mathrm{T}_{2}$ contrast ability due to the $\mathrm{Mn}$ 
doping, accompanied by an appropriated $\mathrm{T}_{1}$ contrast, improved the ability of the UMFNPs to performed dual-mode $\mathrm{T}_{1} / \mathrm{T}_{2}$ contrast, for UMFNPs with $\mathrm{x}>0.5$, as compared with IONP. This effect is reflected in the $r_{2} / r_{1}$ values higher than the obtained with IONP (Figure 5C). Additionally, $\mathrm{r}_{1}$ values obtained at $1.5 \mathrm{~T}$ with UMFNPs with $\mathrm{x}$ $\leq 1.1$ were excellent as compared with gold standard MRI $\mathrm{T}_{1}$ contrast agents such as Gadovist or Resovist with $r_{1}=3.3$ and $8.7 \mathrm{~s}^{-1} \mathrm{mM}^{-1}$ respectively which indicates that UMFNPs are also promising candidates as $\mathrm{T}_{1}$ contrast agents. ${ }^{44}$

Then, we determined that the effect of increasing Mn stoichiometry $\mathrm{x}$ within the ferrite had a major influence on the relaxation times as shown in Figure 5. Depending on the Mn stoichiometry, UMFNPs can be used as $\mathrm{T}_{1}(\mathrm{x} \leq 1.1)$ or dual mode $\mathrm{T}_{1} / \mathrm{T}_{2}$ MRI contrast agents $(x>0.5)$. The observed trend in the $r_{1}$ and $r_{2}$ relaxivity values (Figure SI9A), for increasing $\mathrm{Mn}$ doping levels, obtained at $1.5 \mathrm{~T}$ was reproduced in a $7 \mathrm{~T}$ scanner and shown in Figure 5D (and Figure SI9B)

The relaxometric properties involved in UMFNPs have been attributed to a balance between the inner-sphere and outer-sphere contributions and are influenced by the NP chemical composition (core and coating) and the magnetic properties. ${ }^{2}$ The inner-sphere relaxation contribution is due to the direct coordination of water molecules from the solution to the surface metal ions of the NPs. This relaxation contribution has been reported to increase with increasing $\mathrm{Mn}^{2+}$ doping levels in manganese ferrites, increasing the $\mathrm{r} 1$ relaxivity, because Mn cations provide a lower residence life time of bound water in the inner sphere of the NP. ${ }^{2}$ It is also very influenced by the coating density, thickness, and composition. In contrast, the outer-sphere relaxation is due to the spin-spin interactions between the UMFNPs and the bulk water molecules in the nearby environment. This contribution is highly dependent on the saturation magnetization $\left(\mathrm{M}_{\mathrm{s}}\right)$ between other parameters such as the core size. For UMFNPs with low Mn doping 
$\mathrm{x}<1$ this explained why they had superior $\mathrm{T}_{1}$ and $\mathrm{T}_{2}$ capability than undoped IONP (coherent with Ms measurements). The observed evolution of $r_{1}$ and ${ }_{r 2}$ for increasing Mn stoichiometry, is likely to be caused in a large extend by respectively, the increase of coating thickness and the decrease of the $\mathrm{M}_{\mathrm{s}}$. These two facts partially screen the effect of augmenting the Mn doping level leading to a decrease of both $r_{1}$ and $r_{2}$. This kind of behavior has been already reported for UMFNPs with a Mn stoichiometry between 0.7 and 1.6 and $\mathrm{Cu}$ doped ferrites and was attributed to a complex balance between the outer and the inner-sphere contributions. ${ }^{2,35}$
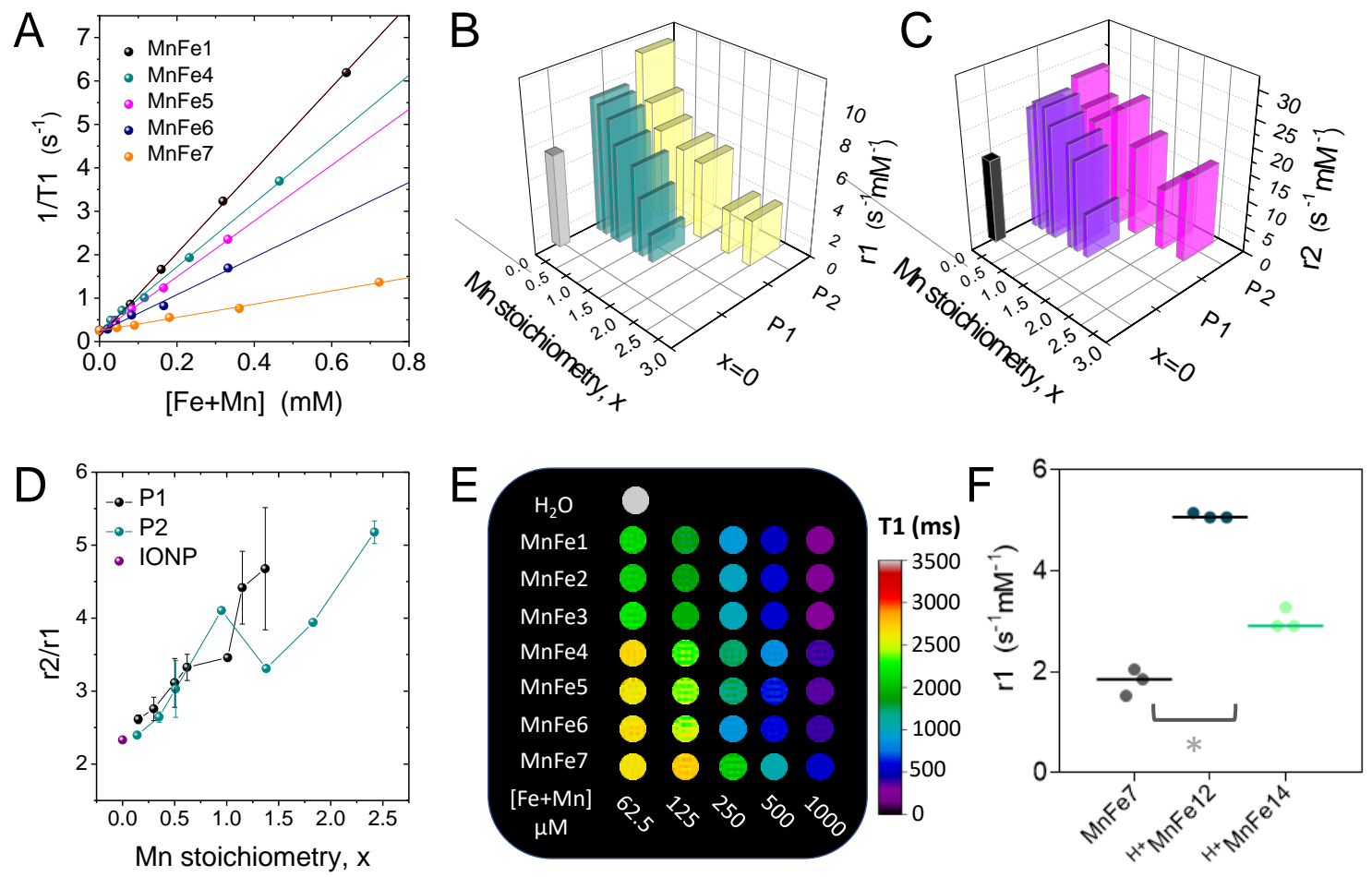

Figure 5. (A) $T_{1}$ relaxation rates of UMFNPs with variable Mn stoichiometry and synthesized P1 protocol. (B) $\mathrm{r}_{1}$ relaxivities measured in $1.5 \mathrm{~T}$ relaxometer of UMFNPs synthesized with P1 (green) and P2 (yellow) compared with r1 of undoped iron oxide ultrasmall NPs (grey bar). (C) $\mathrm{r}_{2}$ relaxivities measured in $1.5 \mathrm{~T}$ relaxometer of UMFNPs synthesized with P1 (violet) and P2 (pink) as compared with $\mathrm{r}_{2}$ of undoped iron oxide ultrasmall NPs (black bar). (D) Comparison of $r_{2} / r_{1}$ relaxivity ratios for UMFNPs obtained with P1 or P2. (E) $7 \mathrm{~T}$ MRI $\mathrm{T}_{1}$ contrast of UMFNPs with increasing $\mathrm{Mn}$ 
stoichiometry prepared with P1 protocol. (F) Statistical analysis (Dunn's multiple comparison test) of the difference in $\mathrm{r}_{1}$ value between MnFe7 prepared with $\mathrm{P} 1$ and ${ }^{\mathrm{H}+} \mathrm{MnFe} 12$ and ${ }^{\mathrm{H}+} \mathrm{MnFe} 14$.

Finally, we studied the difference on relaxometric properties between P1 and P2 synthetic protocols. We compared the specific $r_{1}$ and $r_{2}$ values of each UMFNP obtained with the UMFNPs of P1 and P2 protocols, and determined that for most of the ferrites, $\mathrm{r}_{1}$ values obtained for P2-UMFNPs were similar with no statistical significant differences than those obtained with P1-UMFNPs. Only when $\mathrm{x} \sim 1.4$, the $\mathrm{r}_{1}$ and $\mathrm{r}_{2}$ relaxivities of $\mathrm{MnFe} 7(\mathrm{P} 1)$ were significantly lower $(\mathrm{P}<0.05)$ than $\mathrm{r}_{1}$ and $\mathrm{r}_{2}$ obtained with its counterpart ${ }^{\mathrm{H}+} \mathrm{MnFe} 12$ and similar to ${ }^{\mathrm{H}+} \mathrm{MnFe} 14$ which has $\mathrm{x}=2.42$ (Figure 5F and SI9A). This effect could be due to the thicker citrate coating measured for UMFNPs prepared with the P1 protocol as compared with the P2 protocol. Additionally, the $\mathrm{r}_{2} / \mathrm{r}_{1}$ ratios presented in Figure 5D showed that for both types of NPs, $r_{2} / r_{1}$ is below 3 for $x \leq$ 0.3 and $3 \leq \mathrm{r}_{2} / \mathrm{r}_{1} \leq 10$ for UMFNPs with $\mathrm{x} \geq 0.5$, leading to a similar ability as dual-mode contrast agents. This means that for both protocols $\mathrm{P} 1$ and $\mathrm{P} 2$, the $\mathrm{x}$ value is the main parameter determining whether NPs are good $\mathrm{T}_{1}$ contrast agents or can also be considered dual-mode $\mathrm{T}_{1} / \mathrm{T}_{2}$ contrast agents.

Due to the small differences in the relaxometric properties observed for NPs manufactured with different protocols, we can conclude that both P1 and P2 UMFNPs are excellent $\mathrm{T}_{1}$ and dual-model $\mathrm{T}_{1} / \mathrm{T}_{2}$ contrast agents. Only P1_UMFNPs with high Mn content $(x \geq 1.4)$ present significantly lower $r_{1}$ and $r_{2}$ values and reduced capabilities for positive MRI contrast. Interestingly, most of the obtained $r_{1}$ and $r_{2}$ values were similar to the relaxometric values obtained with UMFNPs prepared with well-known organic 
synthesis, confirming that microwave-assisted methods are suitable for producing efficient MRI contrast agents based on UMFNPs. ${ }^{2,13}$

Tailoring the Fenton/Haber-Weiss catalytic activity. Tumor hypoxia is known to decrease the efficiency of many cancer treatments such as radiotherapy or chemotherapy. There is a general consensus that the oxygen level in hypoxic tumor tissues is poorer than the oxygenation of the corresponding normal tissues and on average it is between $1 \%-2 \% \mathrm{O}_{2}$ or lower. ${ }^{45}$ One of the recent strategies to prevent the impact of cancer hypoxia on the efficiency of therapeutic nanocomposites has been incorporating manganese ferrites into the nanocomposite for Fenton/Haber-Weiss catalysis (Figure 6A). ${ }^{1,3,5,10}$ Often these nanocomposites are used as theranostic agents due to the MRI contrast properties of manganese ferrite NPs. However, to our knowledge, there are no comparative studies that correlate the catalytic behavior of MFNPs with the MRI properties and the stoichiometry of ferrites. Herein, after characterizing the UMFNPs MRI contrast efficiency, we evaluated their Fenton/HaberWeiss catalytic behaviour by monitoring the reaction time courses of $\mathrm{H}_{2} \mathrm{O}_{2}$ depletion through colorimetric assays (following the absorption at $414 \mathrm{~nm}$ ). From this data we determined the apparent turn over number (TTN) (Figure SI10A), defined as the ratio of depleted $\mathrm{H}_{2} \mathrm{O}_{2}$ moles for each mol of catalyst (in this case MnFe4, $\mathrm{x}=0.62$ ) after $24 \mathrm{~h}$ for different $\mathrm{H}_{2} \mathrm{O}_{2}$ concentrations. We obtained a linear dependence between the TTN values and $\left[\mathrm{H}_{2} \mathrm{O}_{2}\right]$, obtaining a value as high as 100 for the highest substrate concentration. .

Figure $6 \mathrm{~B}$ shows the time course of the absorbance decrease at $414 \mathrm{~nm}$ as result of the $\mathrm{H}_{2} \mathrm{O}_{2}$ consumption catalyzed by UMFNPs. This curve fits to a first order exponential decay $\left(\mathrm{k}_{\mathrm{obs}}=0.04 \mathrm{~s}^{-1}, \mathrm{R}^{2}=0.998\right)$ and its linearized data according to 
Equation 1 which corresponds to a first order reaction $\left(\mathrm{k}_{\mathrm{obs}}=0.04 \mathrm{~s}^{-1}, \mathrm{R}^{2}=0.999\right)$. Hence, we confirmed that the kinetics of $\mathrm{H}_{2} \mathrm{O}_{2}$ consumption follows a first-order reaction (respect to $\mathrm{H}_{2} \mathrm{O}_{2}$ concentration) as it has been previously reported by ValdésSolís et al. and others. ${ }^{46}$

$$
-\ln \frac{\mathrm{A}_{t}-\mathrm{A}_{\infty}}{\mathrm{A}_{o}-\mathrm{A}_{\infty}}=k_{o b s} \mathrm{t}
$$

Where $\mathrm{k}_{\mathrm{obs}}$ is the catalytic rate measured experimentally.

The effect of tailoring the Mn stoichiometry $\mathrm{x}$ of UMFNPs, on the Fenton/HaberWeiss catalytic activity was studied for NPs produced with both synthetic protocols P1 and P2. Figure 6C shows that the more Mn within the NP, the higher the catalytic activity. Complementary, the $\mathrm{O}_{2}$ generation increases with the $\mathrm{Mn}$ doping level following the same trend (Figure 6D).

Additionally, the UMFNPs were able to generate $\mathrm{O}_{2}$, in water and cell media, after several $\mathrm{H}_{2} \mathrm{O}_{2}$ additions (Figure $6 \mathrm{E}$ ). We observed that the $\mathrm{O}_{2}$ generation rate was higher in cell culture media than in water, which suggest that the protein corona formation on NPs enhance their catalytic properties. 


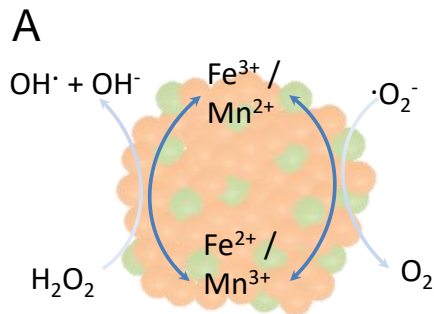

Metal-catalyzed reaction:

$\cdot \mathrm{O}_{2}{ }^{-}+\mathrm{H}_{2} \mathrm{O}_{2} \rightarrow \mathrm{O}_{2}+\mathrm{OH}^{\cdot}+\mathrm{OH}$

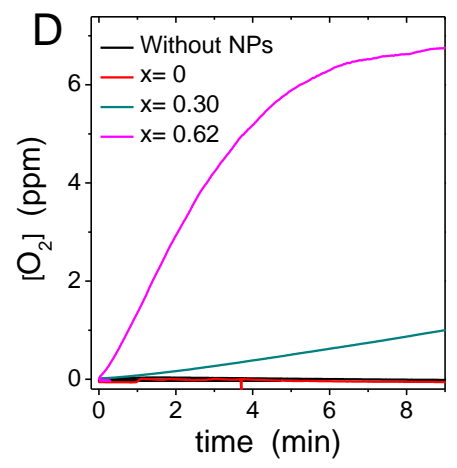

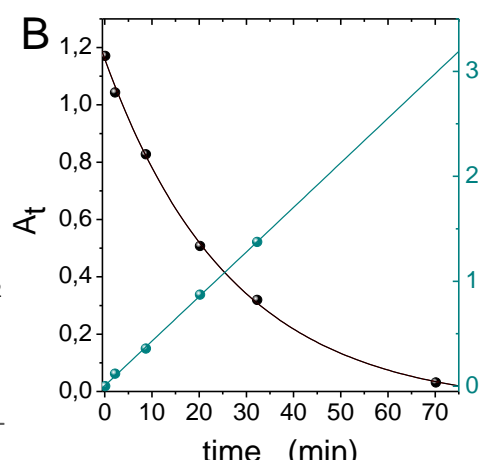

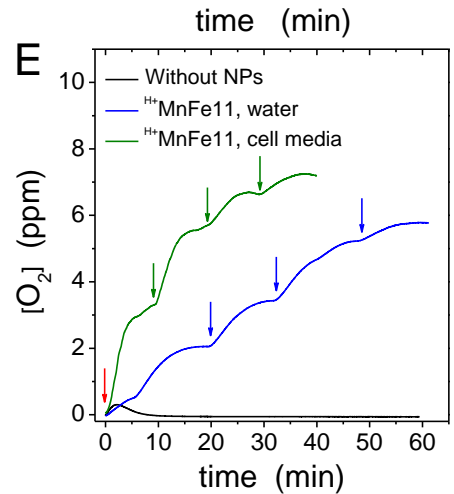

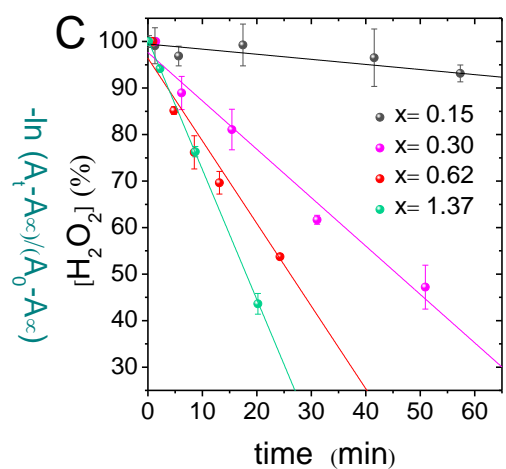

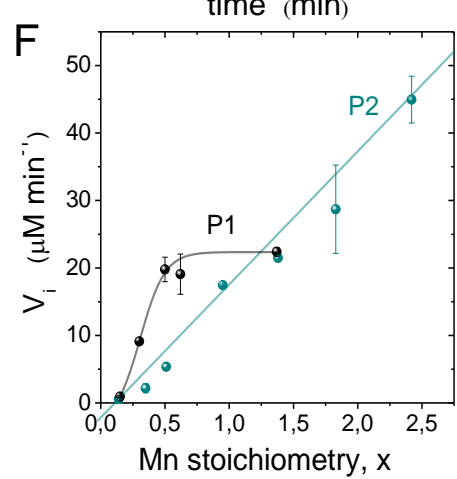

Figure 6. (A) Schematic representation of the Fenton/Haber-Weiss catalysis by UMFNPs. (B) Kinetic trace of the absorbance at $414 \mathrm{~nm}$ during the $\mathrm{H}_{2} \mathrm{O}_{2}$ decomposition by MnFe7 ( $\mathrm{x}=1.38$ ) UMFNPs and fitting to first order exponential decay (left $\mathrm{y}$ axis, $\mathrm{k}_{\mathrm{obs}}=0.04 \mathrm{~s}^{-1}, \mathrm{R}^{2}=0.998$ ) and the linearized data for first order analysis (right y axis, $\mathrm{k}_{\mathrm{obs}}=0.04 \mathrm{~s}^{-1}, \mathrm{R}^{2}=0.999$ ). (C) Temporal conversion of $\mathrm{H}_{2} \mathrm{O}_{2}$ catalyzed by UMFNPs with increasing Mn doping levels. (D) Comparison of $\mathrm{O}_{2}$ generation catalyzed by UMFNPs with different Mn doping levels $(0,0.30$ and 0.62$)$ produced with P1. (E) Example of several $\mathrm{H}_{2} \mathrm{O}_{2}$ addtions (4, pointed with an arrow) of $\mathrm{O}_{2}$ generation performed by ${ }^{\mathrm{H}+} \mathrm{MnFe} 11(\mathrm{x}=0.95)$ in water and cell media. $(\mathrm{F})$ Comparison of initial velocities of $\mathrm{H}_{2} \mathrm{O}_{2}$ comsuption by UMFNPs produced with different synthetic protocols P1 and P2. All kinetic reactions have been performed with constant values of: $\left[\mathrm{Mn}_{\mathrm{x}} \mathrm{Fe}_{(3-\mathrm{x})} \mathrm{O}_{4}\right]=0.53 \mathrm{mM},\left[\mathrm{H}_{2} \mathrm{O}_{2}\right]=0.8 \mathrm{mM}$ at room temperature.

Finally, we compared the catalytic activity of P1 and P2-UMFNPs and we observed significant differences between the two kinds of NPs. Figure 6F illustrates the effect of 
synthetic protocol on the initial degradation rate $\mathrm{V}_{\mathrm{i}}$ of $\mathrm{H}_{2} \mathrm{O}_{2}$ for P1-UMFNPs and P2UMFNPs. The P1-UMFNPs provided an initial and linear relation between the $\mathrm{V}_{\mathrm{i}}$ $(\mu \mathrm{mol} / \mathrm{min})$ and $\mathrm{x}$ that reached a clear plateau from $\mathrm{x} \geq 0.5$. In contrast, the latter shows a slower increase in the initial degradation rate of $\mathrm{H}_{2} \mathrm{O}_{2}$ with increasing $\mathrm{Mn}$ stoichiometry, but a continuous and linear relationship between $\mathrm{Vi}$ and $\mathrm{x}$ throughout the measured range $(0.14 \leq \mathrm{x} \leq 2.42)$. Furthermore, at $\mathrm{x}$ values less than $\mathrm{x}=1.5$, P1UMFNPs provided higher reaction rates than P2-UMFNPs. These evident differences in catalytic behaviour must be due to characteristic differences between P1 and P2UMFNPs. If the atomic structure of UMFNPs is taken into account, Fe and Mn atoms can occupy tetrahedral $\left(\mathrm{T}_{\mathrm{d}}\right)$ and octahedral $\left(\mathrm{O}_{\mathrm{h}}\right)$ sites. In undoped magnetite NPs, there are $\mathrm{Fe}^{3+}$ and $\mathrm{Fe}^{2+}$ cations occupying the $\mathrm{O}_{\mathrm{h}}$ sites, allowing the iron species to be reversibly reduced and oxidized during the Fenton/Haber-Weiss reaction without losing the atomic structure. The $\mathrm{Fe}^{2+}$ in these NPs is known to occupy only $\mathrm{O}_{\mathrm{h}}$ sites, these sites being the most catalytic due to their surface exposure. ${ }^{47}$ The doping of these magnetite NPs with some metal transitions such as Mn has been reported to improve their catalytic activity, as we also showed. ${ }^{48,49}$ The improvement of the reaction mechanism arose from the initial degradation of $\mathrm{H}_{2} \mathrm{O}_{2}$ by $\mathrm{Mn}^{2+}$ to produce $\cdot \mathrm{OH}$ species and accelerated the electron transfer reaction step to produce a more efficient regeneration of the active Fenton/Haber-Weiss $\mathrm{Fe}^{2+}$ species. ${ }^{50}$ It was also reported that the improvement in catalytic activity is highly dependent on the valence of the transition metal and its occupancy within the inverse spinel. ${ }^{47,} 51$ Therefore, although our UMFNPs are composites, different Mn occupancies and atomic organization might play a key role in the catalytic activity of $\mathrm{P} 1$ as compared to P2-UMFNPs (see Figure $6 \mathrm{~F}$ ). $\mathrm{Mn}^{2+}$ cations in P2-UMFNPs (holding a higher amorphous degree than P1-UMFNPs) seem to occupy less exposed sites for catalysis than P1-UMFNPs at low levels of Mn doping, since their 
catalytic behavior is lower for values of $\mathrm{x} \leq 1.4$. In contrast, $\mathrm{Mn}^{2+}$ might occupy higher catalytic sites, probably $\mathrm{O}_{\mathrm{h}}$ sites, within P1-UMFNPs than P2-UMFNPs. These positions appear to fill in a directly proportional way as $\mathrm{x}$ values increase from 0.1 to 0.5 as $\mathrm{Vi}$ increases linearly with increasing $\mathrm{x}$ in this range. Above this maximum the $\mathrm{Mn}^{2+}$ seems to start occupying less catalytic sites within the UMFNP. The initial velocity stays almost constant from $\mathrm{x}=0.5$ to 1.5 . Further experiments with advanced techniques such as X-ray absorption near-edge structure (XANES) would be required to exactly determine the percentage of $\mathrm{Mn}$ and $\mathrm{Fe}$ atoms that are in $\mathrm{T}_{\mathrm{d}}$ or $\mathrm{O}_{\mathrm{h}}$ sites and their corresponding oxidation state. ${ }^{11}$

In order to compare the efficiency of our UMFNPs with other types of nanocatalysts used in preclinical applications as Fenton/Haber-Weiss catalysts, their corresponding turnover frequencies (TOF) were calculated for similar reaction conditions and included in Table 2. Here, TOF was defined as the number of degraded moles of $\mathrm{H}_{2} \mathrm{O}_{2}$ (after a $30 \%$ conversion) per unit of time and unit of catalyst expressed in moles of $\mathrm{Mn}_{\mathrm{x}} \mathrm{Fe}_{3-\mathrm{x}} \mathrm{O}_{4}$. For the sake of simplicity, we only compared some of the UMFNPs with different values of x prepared with the P1 and P2 method (additional data included in SI).

Table 2. Comparison between the catalytic activity of UFMNSP and reported Fenton/Haber-Weiss catalyst and their reaction conditions.

\begin{tabular}{|c|c|c|c|c|c|}
\hline Catalyst & $\mathbf{x}$ & Solvent & $\begin{array}{c}{\left[\mathrm{H}_{2} \mathrm{O}_{2}\right]} \\
(\mathrm{mM})\end{array}$ & $\begin{array}{l}\text { TOF }^{1} \\
\left(\min ^{-1}\right)\end{array}$ & Reference \\
\hline $\mathrm{MnFe} 2$ & 0.30 & $\mathrm{H}_{2} \mathrm{O}$ & 0.8 & $0.019 \pm 0.002$ & This work \\
\hline MnFe5 & 0.5 & $\mathrm{H}_{2} \mathrm{O}$ & 0.8 & $0.037 \pm 0.003$ & This work \\
\hline $\mathrm{MnFe7}$ & 1.37 & $\mathrm{H}_{2} \mathrm{O}$ & 0.8 & $0.043 \pm 0.002$ & This work \\
\hline${ }^{\mathrm{H}+\mathrm{MnFe} 9}$ & 0.35 & $\mathrm{H}_{2} \mathrm{O}$ & 0.8 & $0.0035 \pm 0.0006$ & This work \\
\hline${ }^{\mathrm{H}+\mathrm{MnFe} 11}$ & 0.95 & $\mathrm{H}_{2} \mathrm{O}$ & 0.8 & $0.011 \pm 0.002$ & This work \\
\hline${ }^{\mathrm{H}+\mathrm{MnFe} 12}$ & 1.38 & $\mathrm{H}_{2} \mathrm{O}$ & 0.8 & $0.038 \pm 0.002$ & This work \\
\hline 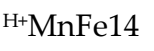 & 2.42 & $\mathrm{H}_{2} \mathrm{O}$ & 0.8 & $0.065 \pm 0.001$ & This work \\
\hline
\end{tabular}




\begin{tabular}{|c|c|c|c|c|c|}
\hline $\mathrm{MnFe} 3$ & 0.50 & $\begin{array}{c}\text { PBS, pH } \\
7.4\end{array}$ & 0.8 & $0.012 \pm 0.006$ & This work \\
\hline${ }^{\mathrm{H}+} \mathrm{MnFe} 11$ & 0.95 & $\begin{array}{c}\text { PBS, } \\
\text { pH } 7.4\end{array}$ & 0.8 & $0.015 \pm 0.001$ & This work \\
\hline${ }^{\mathrm{H}+} \mathrm{MnFe} 14$ & 2.42 & $\begin{array}{c}\text { PBS, } \\
\text { pH } 6.5\end{array}$ & 0.8 & $0.084 \pm 0.004$ & This work \\
\hline $\mathrm{MnFe}_{2} \mathrm{O} 4 / \mathrm{SiO}_{2}$ & 1 & $\begin{array}{c}\text { PBS, } \\
\text { pH } 7.4\end{array}$ & 2.5 & 0.0057 & 3 \\
\hline $\mathrm{MnFe}_{2} \mathrm{O}_{4} / \mathrm{SiO}_{2}$ & 1 & $\begin{array}{c}\text { PBS, } \\
\text { pH } 7.4\end{array}$ & 2.5 & 0.015 & 1 \\
\hline $\mathrm{MOF}^{2}(\mathrm{Fe})$ & - & $\begin{array}{c}\text { MES, } \\
\text { pH } 6.0\end{array}$ & 0.8 & 0.0009 & 52 \\
\hline
\end{tabular}

${ }^{1}$ All TOFs have been calculated for $30 \%$ conversion of $\mathrm{H}_{2} \mathrm{O}_{2} .{ }^{2}$ Metal Organic Framework.

The results shown in Table 2 indicated that our UMFNPs provided higher TOF values than some of the already reported Fenton/Haber-Weiss catalysts. This result is partly due to its smaller size and higher surface-to-volume ratio than the reported $\mathrm{MnFe}_{2} \mathrm{O}_{4} / \mathrm{SiO}_{2}$ composite where the $\mathrm{MnFe}_{2} \mathrm{O}_{4}$ NPs had a diameter of $6 \mathrm{~nm}$ and were embedded in a silica matrix. In any case, we demonstrate that UMFNPs are excellent catalysts for degrading $\mathrm{H}_{2} \mathrm{O}_{2}$ in various solvents and that their catalytic activity can be tailored to demand. We also verified the intracellular depletion of $\mathrm{H}_{2} \mathrm{O}_{2}$ catalyzed by UMFNPs and the impact of the Mn stoichiometry in their catalytic activity (Figure SI10B-C). All these results demonstrate the bioorthogonality of the UMFNPs driven catalysis and the advantages of our microwave-assisted method as an excellent tool for manufacturing Fenton/Haber-Weiss nanocatalysts for biological applications due to its economic and time-efficient synthesis. ${ }^{50}$

Multimodal bioimaging and biodistribution. Before the evaluation of UMFNPs as theranostic agents, the biosafety of the UMFNPs was assessed in vitro (in healthy embryonic fibroblast NIH-3T3 cells and the lung tumor A549 cells) and in vivo with cell cytotoxicity assays and $\mathrm{H} \& \mathrm{E}$ staining examination conducted in C57BL/6JRj mice respectively (study included in the SI). Following the $3 \mathrm{Rs}$ principle in animal 
experimentation and because P2-UMFNPs are the NPs with the broadest Mn stoichiometry $(0.14 \leq \mathrm{x} \leq 2.42)$, we only assayed the biosafety with these P2-UMFNPs in triplicates. These results indicated that in the long term UMFNPs with high Mndoping levels might induce significant cytotoxicity, but low concentrations of UMFNPs could be harmless. The histopathological examination determined similar inflammation scores (1, from 0 to 3 ) for the liver of untreated and intravenously administered UMFNPs. These results are in agreement with already reported biosafety studies of manganese ferrite NPs. ${ }^{2,13}$

In vivo MRI. The in vivo performance as dual-mode $T_{1} / T_{2}$ contrast agents and the corresponding NP biodistribution of UMFNPs was evaluated with two kinds of NPs, which hold both apparent low cytotoxicity but have different Mn stoichiometry, relaxivity, and catalytic activity values: ${ }^{\mathrm{H}+} \mathrm{FeMn} 9(\mathrm{x}=0.35)$ and ${ }^{\mathrm{H}+} \mathrm{FeMn} 11(\mathrm{x}=0.95)$. During the imaging sessions, anatomical images were acquired before and after UMFNP administration to properly allocate the organs of interest. The quantification of the NP biodistribution was carried out by analyzing longitudinal and transversal $\mathrm{T}_{1}$ and $\mathrm{T}_{2}$ parametric maps (Figure 7) from acquired multi-echo images of animals at four different time points before and after intravenous administration (i.v.). This study was performed in groups of $n=3$ animals, and $T_{1}$ and $T_{2}$ values were measured in selected regions of interest (ROIs) for all organs avoiding the inclusion of regions with high relaxivity values which may correspond to fluids like blood or bile. Both kidneys were analyzed separately (right and left) and selected three different ROIs; total, cortex, and medulla to avoid misleading results in the analysis. Figure 7 summarizes the obtained $T_{1}$ and $T_{2}$ parametric maps of animals and the corresponding mean relaxation $T_{1}$ and $T_{2}$ values pooling together all the pre- and post- contrast points. The organs of the two 
main clearance routes of NPs from the bloodstream, the reticuloendothelial and urinary system, showed

some

UMFNP

accumulation.

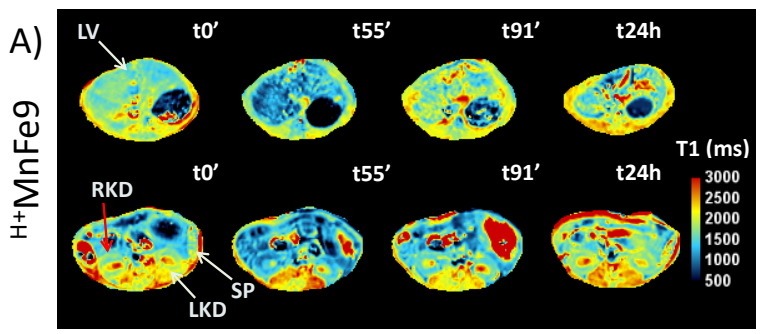

B)
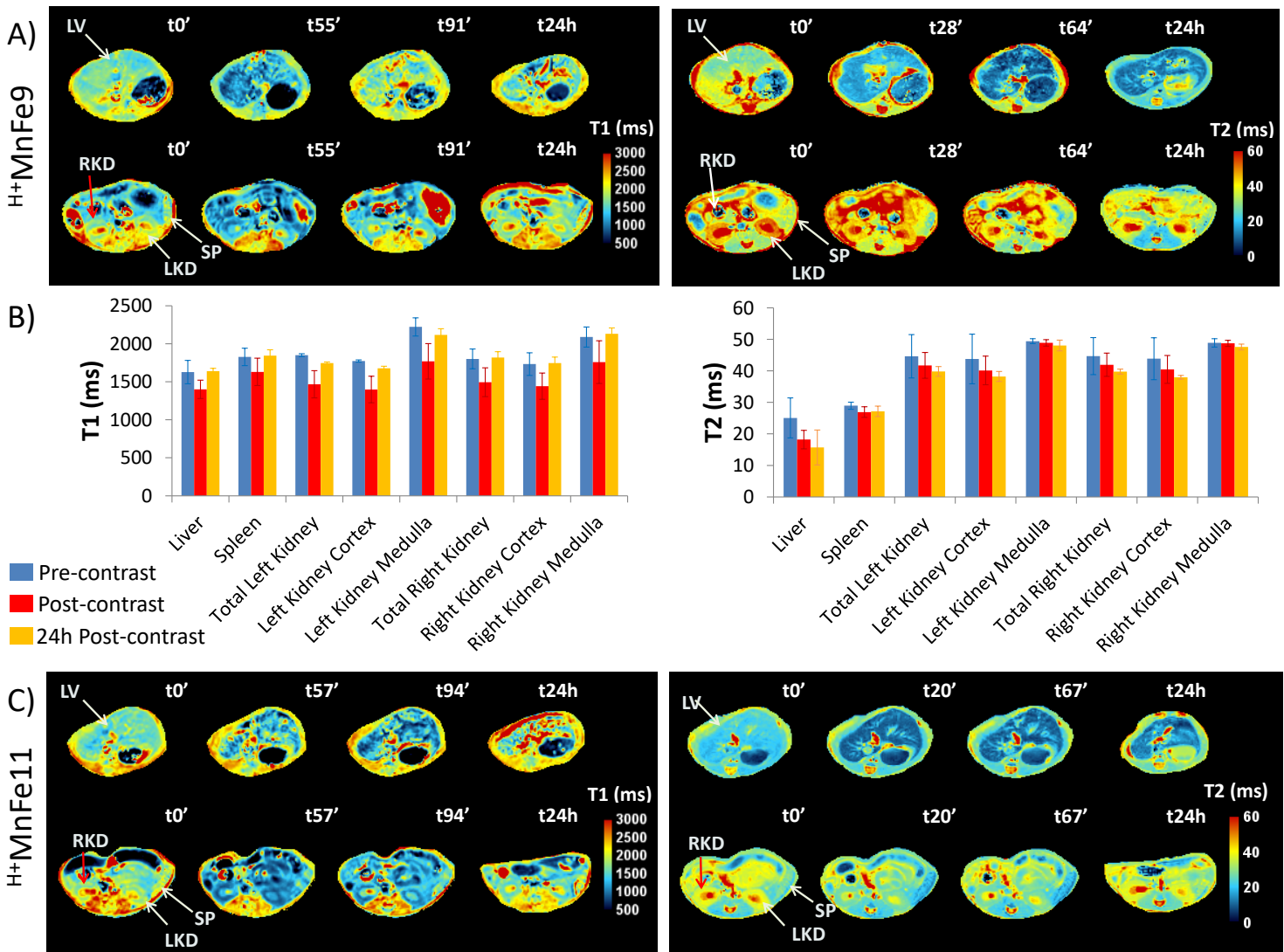

D)
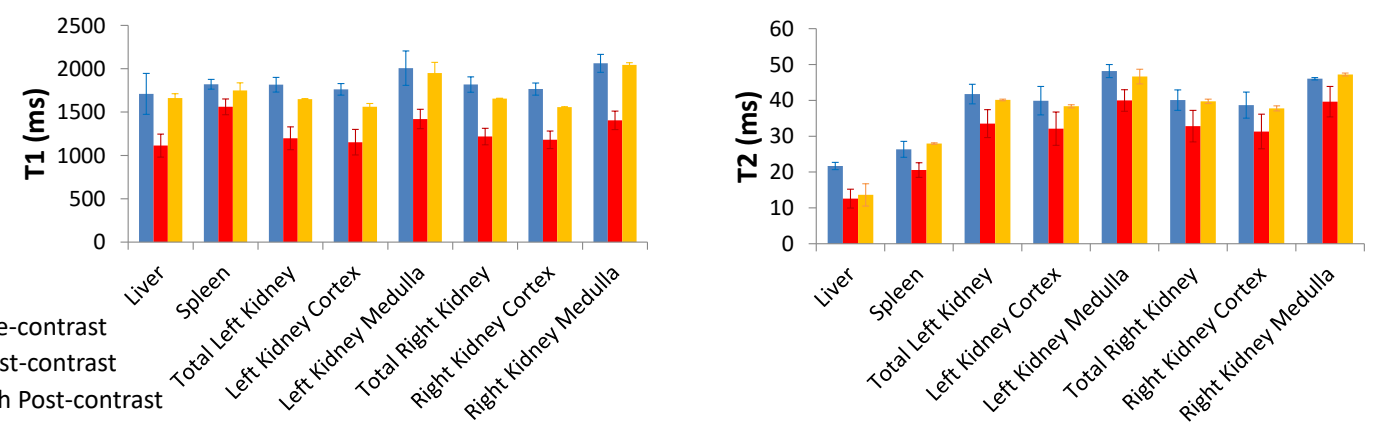

Figure 7. $T_{1}$ and $T_{2}$ relaxation maps $(A, C)$ at two different locations of the abdomen of a mouse showing the liver (LV) at the top rows in both images and the spleen (SP) and the right and left kidneys (RKD, LKD) at the bottom row in both images. Four different time points are presented to reflect the changes in $\mathrm{T}_{1}$ and $\mathrm{T}_{2}$ values before $\left(\mathrm{t}^{\prime}\right)$ and different minutes/hours after the intravenous injection of ${ }^{\mathrm{H}+} \mathrm{MnFe} 9(\mathrm{~A}, \mathrm{x}=0.35)$ and ${ }^{\mathrm{H}+} \mathrm{MnFe} 11(\mathrm{C}, \mathrm{x}=0.95)$ UMFNPs. (B, D) Mean $( \pm \mathrm{SD}) \mathrm{T}_{1}$ and $\mathrm{T}_{2}$ relaxation values 
obtained for different organs pre- (blue), post- (red) injection and (yellow) $24 \mathrm{~h}$ postinjection of the ${ }^{\mathrm{H}+} \mathrm{MnFe} 9$ (B) and ${ }^{\mathrm{H}+} \mathrm{MnFe} 11$ (D) UMFNPs.

A detailed MRI analysis determined that both ${ }^{\mathrm{H}+} \mathrm{FeMn} 9(\mathrm{x}=0.35)$ and ${ }^{\mathrm{H}+} \mathrm{FeMn} 11(\mathrm{x}=$ $0.95)$ behaved as efficient dual $\mathrm{T}_{1} / \mathrm{T}_{2}$ MRI contrast agents. ${ }^{\mathrm{H}+} \mathrm{FeMn} 11$ NPs induced higher differences of $T_{1}$ and $T_{2}$ after administration and thus higher contrast than ${ }^{\mathrm{H}+} \mathrm{FeMn} 9$, probably due to higher $\mathrm{r}_{2} / \mathrm{r}_{1}$ values (Figure S13, Table S3). Comparing the biodistribution of the two kinds of UMFNPs and the information given in both $\mathrm{T}_{1}$ and $\mathrm{T}_{2}$ maps, it can be observed that thanks to the dual mode analysis we obtained complementary information about the fate of our UMFNPs in vivo.

The T1 analysis showed, for both ${ }^{\mathrm{H}+} \mathrm{FeMn} 9$ and ${ }^{\mathrm{H}+} \mathrm{FeMn} 11$, a decrease of the $\mathrm{T}_{1}$ relaxation time after UMFNPs administration in liver, spleen and kidneys. However, the $\mathrm{T}_{1}$ relaxation time was recovered with the time in liver and kidneys (Table SI3) but not in the spleen. This could indicate the clearance of UMFNPs from both organs, or a fast NP degradation. However, it is known that NPs are not rapidly eliminated from the liver in contrast with the fast renal clearance though the urine. ${ }^{53}$ In fact, this temporal enhancement of $T_{1}$ in the liver did not correlate with the results obtained with the $T_{2}$ map analysis. In this case, the $\mathrm{T}_{2}$ analysis showed similar time-dependent and longlasting $\mathrm{T}_{2}$ decrease in the liver of mice administered with ${ }^{\mathrm{H}+} \mathrm{FeMn} 9$ or ${ }^{\mathrm{H}+} \mathrm{FeMn} 11$ NPs. In order to clarify where UMFNPs were accumulated, both histological and mass spectrometry determination of $\mathrm{Fe}$ and $\mathrm{Mn}$ in liver were performed at $24 \mathrm{~h}$ after the i.v. administration. Results presented in Figure 8 demonstrated the presence of UMFNPs of both kinds of NPs in liver at 24h. The mass spectrometry analysis of Mn in the liver determined a 2.8 fold-increase of $\mathrm{Mn}$ in the liver of mice administered with ${ }^{\mathrm{H}+} \mathrm{FeMn} 11$ as compared with ${ }^{\mathrm{H}+} \mathrm{FeMn} 9$. This is consistent with the 2.7 fold increase of Mn content 
in ${ }^{\mathrm{H}+} \mathrm{FeMn} 11(\mathrm{x}=0.95)$ relative to ${ }^{\mathrm{H}+} \mathrm{FeMn} 9(\mathrm{x}=0.35)$. Histological samples stained with Perl's Prussian blue showed small blue dots corresponding with the presence of $\mathrm{Fe}^{3+}$ in agglomerated UMFNPs with sizes below $10 \mu \mathrm{m}$.
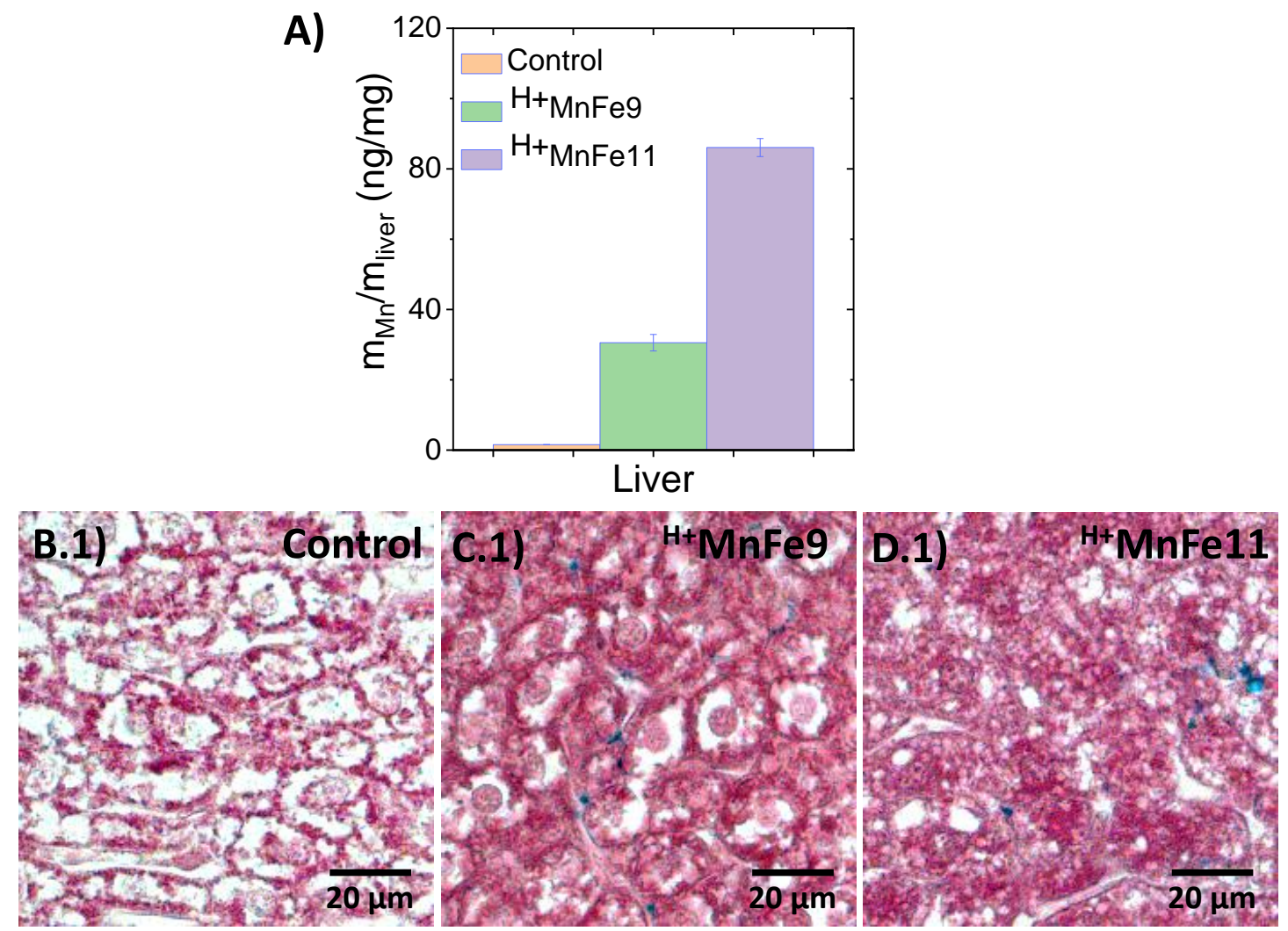

Figure 8. Ex vivo determination by ICP-MS of Mn accumulation in liver after 24h. The mass of Mn was determined for dried mass of liver. (A) Histological determination of the UMFNPs presence in liver (B.1-D.1) and kidneys (B.2-D.2) by Perl's Prussian blue staining of $\mathrm{Fe}^{3+} . \mathrm{B}, \mathrm{C}$ and $\mathrm{D}$ correspond to tissues from control mice (not administered with UMFNPs) administered with ${ }^{\mathrm{H}+} \mathrm{FeMn} 9$, and ${ }^{\mathrm{H}+} \mathrm{FeMn} 1$, respectively.

These results denoted a time-dependent change of relaxometric properties of UMFNPs in vivo, evident in the $\mathrm{T} 1$ contrast. It seems that we are detecting the time point of massive accumulation of our UMFNPs after being uptaken by the phagocytic Kupffer cells, the main cells for foreign particles processing in the liver. When confined in cells, the r1 value of magnetic NPs has been reported to decrease in a higher extent 
than its corresponding $r_{2}$ relaxivity value, leading to an increase of $r_{2} / r_{1}$ ratio and $T_{2}$ governing the MRI contrast. ${ }^{54-56}$ This can explain the temporal enhancement of the $\mathrm{T}_{1}$ signal after UMFNP accumulation in the liver. We verified in solution the larger decrease of $r_{1}$ respect to the decrease of $r_{2}$ in agglomerated UMFNPs. However due to the heterogeneity of the aggregation process, we could not define the differences between UMFNPs with different Mn doping level. In the MRI biodistribution experiments, this time point was dependent on the kind of UMFNPs. Because the increase of Mn doping level lead to an increase of coating thickness (and there are not significant differences between $d_{h}$ and zeta potential), it can be assumed that this fact is partly influencing the Kupffer cell uptake and accumulation process.

Radiolabelling of UMFNPs. Positron emission tomography combined with computed tomography (PET/CT) is the most sensitive technique for a rapid quantifiable analysis of NP biodistribution. ${ }^{57}$ Quantification of the accumulation of NPs in the different organs is not possible with MRI. Although MRI is better for cross section imaging, and soft tissue, and inflammation imaging. Therefore, the combination of MRI/PET/CT is very powerful for molecular imaging. ${ }^{27}$ Here, we demonstrate that UMFNPs with tailored Mn stoichiometry ( $\mathrm{x}=0.31,1.15$ and 2.54$)$ are easily core-doped with traces of ${ }^{68} \mathrm{Ga}$ for positron emission tomography (PET) as we have previously demonstrated for undoped ultrasmall iron oxide NPs. ${ }^{27}$ The physicochemical characterization of the radiolabeled UMFNPs prepared with protocol P2 (with enhanced metal doping) showed a negligible influence on the core size, zeta potential and hydrodynamic ratio, a slight decrease of the of the magnetic relaxivities and a slight increase of the catalytic activity (Table SI4-6) as compared to cold UMFNPs. We studied the biodistribution of only one of the radiolabeled UMFNPs because they have 
similar size and coating composition $\left({ }^{68 \mathrm{Ga}} \mathrm{Mn}_{0.31} \mathrm{Fe}_{2.69} \mathrm{O}_{4}, \mathrm{r} 1=5.85 \mathrm{~s}^{-1} \mathrm{mM}^{-1}\right.$ and $\mathrm{r} 2=$ $9.33 \mathrm{~s}^{-1} \mathrm{mM}^{-1}$ and TOF $=0.009 \mathrm{~min}^{-1}$ ). Thanks to its radiolabeling with ${ }^{68} \mathrm{Ga}$, it was possible to determine that these citrate-coated UMFNPs remained in the circulation after one hour of intravenous administration. About $10 \%$ of the $\mathrm{ID} / \mathrm{cm}^{3}$ was still present in the bloodstream after 60 minutes (estimated from the signal in the heart). These results are consistent with our previous work with citrate-coated ultrasmall iron oxide NPs and indicate that it might be possible achieving specific tissue accumulation with core-doped UMFNPs labelled with targeting molecules. ${ }^{20}$
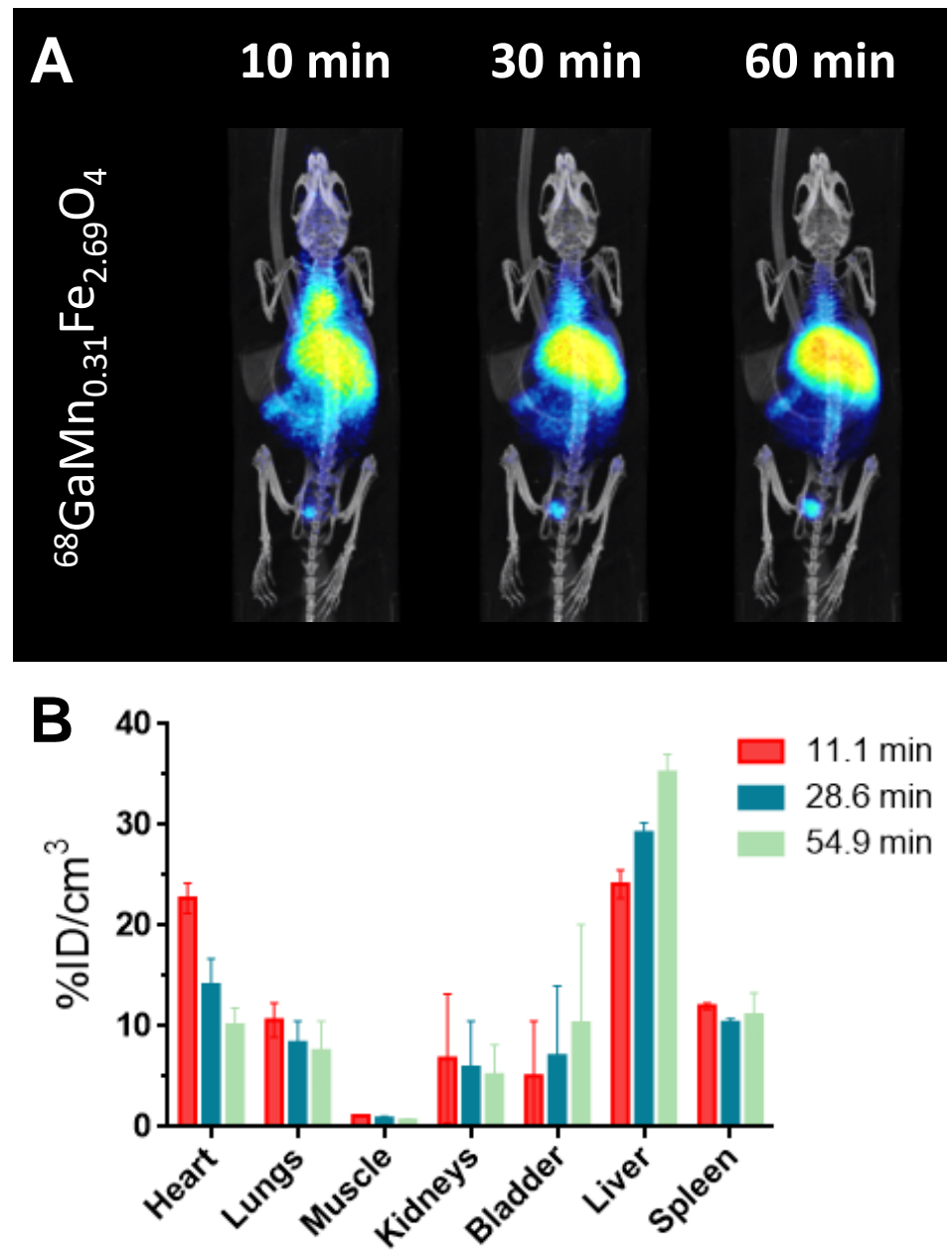

Figure 9. In vivo biodistribution study. (A) PET images at different time points of ${ }^{68} \mathrm{Ga}$ UMFNPs $(x=0.31)$. (B) In vivo quantification of the biodistribution at different time points of the 68Ga-UMFNPs in the main organs $(n=2)$. 
PET experiments, shown in Figure 9, also showed that UMFNPs are cleared from the bloodstream through expected organs, mainly liver, bladder and kidneys, as consequence of the size of these nanoparticles. Figure 9 confirms the MRI results and shows that UMFNPs tended to be trapped in the liver and spleen, the main organs of the mononuclear phagocytic system. However, a considerable amount of UMFNPs are first cleared by the kidneys and subsequently excreted by the urine which explains the increased value of activity in the bladder reaching a $10 \%$ after $1 \mathrm{~h}$. This biodistribution and clearance mechanism is typical of NPs with a hydrodynamic size between 10-20 nm at the limit between hepatic elimination and renal filtration. ${ }^{20,58}$

\section{CONCLUSIONS}

In summary, we successfully synthesize water soluble citrate coated UMFNPs with well-controlled size $(\approx 4 \mathrm{~nm}$ diameter $)$ and variable $\mathrm{Mn}$ doping $\left(\mathrm{Mn}_{\mathrm{x}} \mathrm{Fe}_{3-\mathrm{x}} \mathrm{O}_{4}, 0.1 \leq \mathrm{x} \geq\right.$ 2.4) through a microwave-assisted one-pot method. The UMFNPs showed an inverse spinel standard manganese ferrite structure, and had good catalytic activity as compared with UMFNPs produced with organic or polyol methods. We generated a series of particles with tuneable magnetic relaxivities (both $\mathrm{r}_{1}$ : $1.6-10.6 \mathrm{mM}^{-1} \mathrm{~s}^{-1}$, and $\mathrm{r}_{2}$ : 7.5-29.9 $\mathrm{mM}^{-1} \mathrm{~s}^{-1}$ ), which could be used as $\mathrm{T}_{1}$ or dual-mode $\mathrm{T}_{1}$ and $\mathrm{T}_{2}$ MRI contrast agents depending on the Mn doping level. Furthermore, these UMFNPs catalyzed several cycles of $\mathrm{H}_{2} \mathrm{O}_{2}$ depletion through the Fenton/Haber-Weiss reaction, generating $\mathrm{O}_{2}$ as ultimate reaction product. As such, this type of NPs might be used to enhance the therapeutic effect of traditional anticancer treatments (chemotherapy, photodynamic therapy, etc) based on nanocomposites preventing the impact of cancer hypoxia. Finally, 
these UMFNPs were colloidally stable and demonstrate moderately high blood circulation times determined by PET and MRI.

In conclusion, our results provide a fast and efficient synthetic protocol to produce UMFNPs with tailored chemical composition. The correlation of their corresponding physicochemical, magnetic and catalytic properties with their in vivo MRI/PET/CT contrast and biodistribution may benefit the optimization of nanocompostites designed for catalytic therapies towards their practical biomedical applications. 


\section{MATERIALS AND METHODS}

Materials. The chemical reagents iron trichloride hexahydrate $\left(\mathrm{FeCl}_{3} \cdot 6 \mathrm{H}_{2} \mathrm{O}\right)$, manganese dichloride tetrahydrate $\left(\mathrm{MnCl}_{2} \cdot 4 \mathrm{H}_{2} \mathrm{O}\right)$, citric acid trisodium salt dihydrate $\left(\mathrm{Na}_{3} \mathrm{C}_{6} \mathrm{H}_{5} \mathrm{O}_{7} \cdot 2 \mathrm{H}_{2} \mathrm{O}\right)$ and hydrazine monohydrate were purchased from Sigma-Aldrich and stored in a desiccator. All the syntheses were carried out with $\mathrm{H}_{2} \mathrm{O}$ nanopure water as solvent. ${ }^{68} \mathrm{Ga}\left(\mathrm{t}_{1 / 2}=68 \mathrm{~min}, \beta+\right.$ emmisor $89 \%$ and EC $\left.11 \%\right)$ was obtained from a ${ }^{68} \mathrm{Ge} /{ }^{68} \mathrm{Ga}$ generator system (ITG Isotope Technologies, Garching GmbH, Germany) as a solution of ${ }^{68} \mathrm{GaCl}_{3}$ (aq) by eluting with $4 \mathrm{ml}$ of $\mathrm{HCl} 0.05 \mathrm{M}$ (free metal traces).

Synthesis of UMFNPs. To produce UMFNPs with variable $\mathrm{Mn}$ and $\mathrm{Fe}$ stoichiometries $\left(\mathrm{Mn}_{\mathrm{x}} \mathrm{Fe}_{3-\mathrm{x}} \mathrm{O}_{4}\right)$, different $\left[\mathrm{FeCl}_{3}\right] /\left[\mathrm{MnCl}_{2}\right]$ precursor ratios were used for the microwave assisted synthesis as specified in Table 1 . Briefly, in a $10 \mathrm{ml}$ tube, the correspondent amount of $\mathrm{FeCl}_{3} \cdot 6 \mathrm{H}_{2} \mathrm{O}$ and $\mathrm{MnCl}_{2} \cdot 4 \mathrm{H}_{2} \mathrm{O}$ were mixed with $20 \mathrm{mg}$ of citric acid trisodium salt dehydrate and $0.25 \mathrm{ml}$ of hydrazine. In all syntheses, the 0.25 $\mathrm{ml}$ of hydrazine hydrate were added to the tube just before starting the synthesis in the microwave. The protocol P1 (MnFe1-MnFe7) was carried out using $2.25 \mathrm{~mL}$ of nanopure water while the protocol P2 (MnFe8-MnFe14) used $2.25 \mathrm{~mL}$ of $0.022 \mathrm{M} \mathrm{HCl}$ solution. The radiolabeled UMFNPs were produced similarly to $\mathrm{P} 2$ but with the $\mathrm{HCl}$ solution containing traces of ${ }^{68} \mathrm{GaCl}_{3}(0.001 \mathrm{mM})$ The radiolabeling yield was around $50 \%$ after 30 minutes from elution The microwave was programmed with the follow steps: 1 min ramping from room temperature to $100{ }^{\circ} \mathrm{C}$, maintaining $10 \mathrm{~min}$ at $100{ }^{\circ} \mathrm{C}$, and cooling down to room temperature. All UMFNPs were purified with a PD-10 column to eliminate the excess of salts and unreacted precursors. For animal administration, $500 \mu \mathrm{L}$ of $1 \mathrm{mg} / \mathrm{mL}$ UMFNP solution was filtered through Amicon $30 \mathrm{~K}$ and the retentate was resuspended in $500 \mu \mathrm{L}$ of saline solution $(0.9 \% \mathrm{NaCl}$ in water). 
Magnetic characterization. Sample preparation for magnetic measurements was performed by placing a known volume of each suspension into a piece of cotton wool and allowing it to dry at room temperature. The dried wool was then placed inside a gelatine capsule for the magnetic characterization. Magnetic measurements were performed in a Quantum Design (USA) MPMS-XL SQUID magnetometer. Field dependent magnetization was recorded at $300 \mathrm{~K}$ in the field ranges between $-1600 \mathrm{kA} / \mathrm{m}$ and $1600 \mathrm{kA} / \mathrm{m}$. In addition, temperature dependence of the AC magnetic susceptibility was recorded from 2 to $80 \mathrm{~K}$, at a frequency of $11 \mathrm{~Hz}$ and using a magnetic field amplitude of 4.1 Oe.

Relaxometry Measurements. The spin-lattice and spin-spin relaxation times $\left(\mathrm{T}_{1}\right.$ and $\mathrm{T}_{2}$ ) were measured for five concentrations of each UMFNP sample in a Bruker Minispec MQ60 (Bruker Biospin $\mathrm{GmbH}$ ) contrast agent analyzer at $1.5 \mathrm{~T}$ and $37^{\circ} \mathrm{C}$. Additionally, $\mathrm{T}_{1}$ and $\mathrm{T}_{2}$ were also measured in a $7 \mathrm{~T}$ horizontal bore Bruker Biospec USR 70/30 MRI system (Bruker Biospin $\mathrm{GmbH}$ ). The relaxivities $r_{1}$ and $r_{2}$ were plotted against the Mn stoichiometry values and the corresponding synthetic protocol (P1 or P2).

Catalytic studies. Fenton/Haber-Weiss reaction was studied by determining the temporal decrease of $\left[\mathrm{H}_{2} \mathrm{O}_{2}\right]$ catalyzed by UMFNPs and temporal increase of $\left[\mathrm{O}_{2}\right]$ concentrations in the reaction solution containing an initial concentration of $\left[\mathrm{H}_{2} \mathrm{O}_{2}\right]_{=}=0.8 \mathrm{mM}$ and $\left[\mathrm{Mn}_{\mathrm{x}} \mathrm{Fe}_{3-\mathrm{x}} \mathrm{O}_{4}\right]=0.53 \mathrm{mM}$. The temporal measurements of $\left[\mathrm{H}_{2} \mathrm{O}_{2}\right]$ were done using an colorimetric enzyme assay with horseradish peroxidase (HRP) and 2,2'Azino-bis(3-ethylbenzothiazoline-6-sulfonic acid) diammonium salt (ABTS) $\left(\mathrm{H}_{2} \mathrm{O}_{2}+\right.$ ABTS $\stackrel{\mathrm{HRP}}{\rightarrow} 2 \mathrm{H}_{2} \mathrm{O}+$ oxidized ABTS). The absorbance was measured at $414 \mathrm{~nm}$ where we did not observe any crosstalk with the absorbance of UMFNPs. We performed the study in $96-$ well plates where $200 \mu \mathrm{L}$ of a solution of $0.5 \mathrm{mg} / \mathrm{mL} \mathrm{HRP}$ and $1 \mathrm{mg} / \mathrm{mL}$ 
ABTS were mixed with $10 \mu \mathrm{L}$ of the reaction solution $\left(\mathrm{H}_{2} \mathrm{O}_{2} / \mathrm{UMFNPs}\right)$ at different time points. The TTN calculation was performed at $24 \mathrm{~h}$ for a constant concentration of $0.53 \mathrm{mM}$ of $\mathrm{MnFe} 4$ and a variable concentration of $\mathrm{H}_{2} \mathrm{O}_{2}$ between 0.8 and $51.2 \mathrm{mM}$. The $\left[\mathrm{O}_{2}\right]$ was measured with PICO2 fiber-optical oxygen meter connected to the oxygen dipping probe OPDIP20 from PyroScience GmbH.

Magnetic Resonance Imaging (MRI). The aforementioned MRI scanner was used to determine the feasibility as $\mathrm{T}_{1}$ and/or dual mode $\mathrm{T}_{1} / \mathrm{T}_{2}$ image contrast of the prepared UMFNPs in mice, as well as for the UMFNP biodistribution studies. Animal experiments were conducted in CIC biomaGUNE animal facility, which holds a full accreditation from the AAALAC. All animal procedures were approved by our Institutional animal care and committee and local authorities (Diputación Foral de Guipuzcoa, Spain). During the in vivo studies, two groups (one for each type of UMFNP) of $n=3$ mice were administered intravenously. Mice were eight weeks old C57BL/6JRj female mice (20 mg body weight) from Janvier, France.

Radiolabeling and Positron Emission Tomography (PET). The reaction to synthesized ${ }^{68} \mathrm{Ga}$ labelled manganese ferrites was similar to the one used for manganese ferrites, but $1 \mathrm{ml}$ of ${ }^{68} \mathrm{GaCl}_{3}$ (in $0.05 \mathrm{M} \mathrm{HCl}$ ) eluted from the ${ }^{68} \mathrm{Ge} /{ }^{68} \mathrm{Ga}$ generator, was added to the iron chloride and manganese chloride precursors and sodium citrate solution. Then, hydrazine hydrate was added and the reaction was performed in the microwave reaction system, at $100^{\circ} \mathrm{C}$ during 10 minutes. After purification through PD10 column the solution was filtered (30K Dalton Amicon filters) and nanoparticles were resuspended in saline solution $(0.9 \% \mathrm{NaCl})$ to be immediately administered intravenously to the mice before performing a PET-scan for a $1 \mathrm{~h}$ monitoring. In vivo PET/CT imaging in mice (eight weeks old C57BL/6JRj female mice) was performed using a nanoPET/CT small-animal imaging system (Molecubes, Gentt, Belgium). 100 
$\mu 1$ of ${ }^{68} \mathrm{Ga}$ manganese ferrites in saline solution containing a radioactivity of about $3 \mathrm{MBq}$ were injected to the mice. The dynamic PET images were reconstructed in 22 frames of $15 \mathrm{~s}$ (4 frames), $30 \mathrm{~s}$ (4 frames), 1 min (4 frames), 2 min (4 frames), $5 \mathrm{~min}$ (4 frames), $12.5 \min$ (2 frames), taking averaged data from time points centered at 10, 30, 60 minutes for the data analysis. Quantification for biodistribution of ${ }^{68} \mathrm{Ga}$ manganese ferrites was made with a statistic of $n=2$. Animal Ethics: Experiments performed at CIC biomaGUNE were approved by the Ethical Committee of the Institution and by the corresponding authorities.

For more details regarding the experimental section and additional results, the reader is referred to the Supporting Information.

\section{ASSOCIATED CONTENT}

Supporting Information: Supplemental Methods, Tables S1-S6 and Figures S1-S13 were included in the supporting information.

\section{AUTHOR INFORMATION}

\section{Corresponding authors:}

Email: scarregal@cicbiomagune.es

Email:jruizcabello@cicbiomagune.es

\section{ACKNOWLEDGEMENTS}

SCR is supported by the Ministerio de Ciencia e Innovación (PID2019-106139RA-100). JRC is supported by grants from the Ministerio de Economía, Industria y Competitividad (MEIC) (SAF2017-84494-C2-R), and from the Gobierno Vasco, Dpto. Industria, Innovación, Comercio y Turismo under the ELKARTEK Program (Grant No. 
KK-2019/bmG19). JRC received funding from the BBVA Foundation (Ayudas a Equipos de investigación científica Biomedicina 2018) and from La Caixa. YFA. received funding from Santander-Universidad Zaragoza Fellowship program. LG. acknowledges financial support from the Ramón y Cajal program (RYC-2014-15512). CIC biomaGUNE is supported by the Maria de Maeztu Units of Excellence Program from the Spanish State Research Agency - Grant No. MDM-2017-0720. Authors would like to acknowledge the use of Servicio General de Apoyo a la Investigación-SAI, Universidad de Zaragoza.

\section{REFERENCES}

1. Kim, J.; Kim, H. Y.; Song, S. Y.; Go, S.-h.; Sohn, H. S.; Baik, S.; Soh, M.; Kim, K.; Kim, D.; Kim, H.-C.; Lee, N.; Kim, B.-S.; Hyeon, T., Synergistic Oxygen Generation and Reactive Oxygen Species Scavenging by Manganese Ferrite/Ceria Codecorated Nanoparticles for Rheumatoid Arthritis Treatment. ACS Nano 2019, 13 (3), 3206-3217.

2. Miao, Y.; Xie, Q.; Zhang, H.; Cai, J.; Liu, X.; Jiao, J.; Hu, S.; Ghosal, A.; Yang, Y.; Fan, H., Composition-Tunable Ultrasmall Manganese Ferrite Nanoparticles: Insights into their In Vivo T1 Contrast Efficacy. Theranostics 2019, 9 (6), 1764-1776.

3. Kim, J.; Cho, H. R.; Jeon, H.; Kim, D.; Song, C.; Lee, N.; Choi, S. H.; Hyeon, T., Continuous O-2-Evolving MnFe2O4 Nanoparticle-Anchored Mesoporous Silica Nanoparticles for Efficient Photodynamic Therapy in Hypoxic Cancer. J. Am. Chem. Soc. 2017, 139 (32), 10992-10995.

4. Pardo, A.; Pelaz, B.; Gallo, J.; Bañobre-López, M.; Parak, W. J.; Barbosa, S.; del Pino, P.; Taboada, P., Synthesis, Characterization, and Evaluation of Superparamagnetic Doped Ferrites as Potential Therapeutic Nanotools. Chemistry of Materials 2020, 32, 2220-2231.

5. Yin, S.-Y.; Song, G.; Yang, Y.; Zhao, Y.; Wang, P.; Zhu, L.-M.; Yin, X.; Zhang, X.-B., Persistent Regulation of Tumor Microenvironment via Circulating Catalysis of MnFe2O4@Metal-Organic Frameworks for Enhanced Photodynamic Therapy. Advanced Functional Materials 2019, 29 (25), 1901417.

6. Han, J.; Yoon, J., Supramolecular Nanozyme-Based Cancer Catalytic Therapy. ACS Applied Bio Materials 2020.

7. Szatrowski, T. P.; Nathan, C. F., Production of Large Amounts of Hydrogen Peroxide by Human Tumor Cells. Cancer Research 1991, 51 (3), 794.

8. Jernigan, N.; Naik, J.; Weise-Cross, L.; Detweiler, N.; Herbert, L.; Yellowhair, T.; Resta, T., Contribution of reactive oxygen species to the pathogenesis of pulmonary arterial hypertension. PLOS ONE 2017, 12, e0180455.

9. Halliwell, B.; Clement, M. V.; Long, L. H., Hydrogen peroxide in the human body. FEBS letters 2000, 486 (1), 10-3. 
10. Ranji-Burachaloo, H.; Gurr, P. A.; Dunstan, D. E.; Qiao, G. G., Cancer Treatment through Nanoparticle-Facilitated Fenton Reaction. ACS Nano 2018, 12 (12), 11819-11837.

11. Lasheras, X.; Insausti, M.; de la Fuente, J. M.; Gil de Muro, I.; CastellanosRubio, I.; Marcano, L.; Fernández-Gubieda, M. L.; Serrano, A.; Martín-Rodríguez, R.; Garaio, E.; García, J. A.; Lezama, L., Mn-Doping level dependence on the magnetic

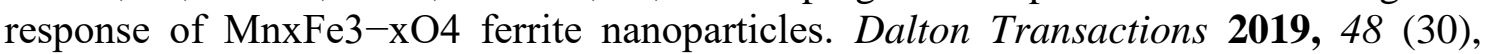
11480-11491.

12. Lu, J.; Ma, S. L.; Sun, J. Y.; Xia, C. C.; Liu, C.; Wang, Z. Y.; Zhao, X. N.; Gao, F. B.; Gong, Q. Y.; Song, B.; Shuai, X. T.; Ai, H.; Gu, Z. W., Manganese ferrite nanoparticle micellar nanocomposites as MRI contrast agent for liver imaging. Biomaterials 2009, 30 (15), 2919-2928.

13. Pernia Leal, M.; Rivera-Fernández, S.; Franco, J. M.; Pozo, D.; de la Fuente, J. M.; García-Martín, M. L., Long-circulating PEGylated manganese ferrite nanoparticles for MRI-based molecular imaging. Nanoscale 2015, 7 (5), 2050-2059.

14. Tong, S.; Quinto, C. A.; Zhang, L.; Mohindra, P.; Bao, G., Size-Dependent Heating of Magnetic Iron Oxide Nanoparticles. ACS Nano 2017, 11 (7), 6808-6816.

15. Ni, D.; Bu, W.; Ehlerding, E. B.; Cai, W.; Shi, J., Engineering of inorganic nanoparticles as magnetic resonance imaging contrast agents. Chemical Society Reviews 2017, 46 (23), 7438-7468.

16. Shin, T.-H.; Choi, J.-s.; Yun, S.; Kim, I.-S.; Song, H.-T.; Kim, Y.; Park, K. I.; Cheon, J., T1 and T2 Dual-Mode MRI Contrast Agent for Enhancing Accuracy by Engineered Nanomaterials. ACS Nano 2014, 8 (4), 3393-3401.

17. Thapa, B.; Diaz-Diestra, D.; Santiago-Medina, C.; Kumar, N.; Tu, K.; BeltranHuarac, J.; Jadwisienczak, W. M.; Weiner, B. R.; Morell, G., T1- and T2-weighted Magnetic Resonance Dual Contrast by Single Core Truncated Cubic Iron Oxide Nanoparticles with Abrupt Cellular Internalization and Immune Evasion. ACS Applied Bio Materials 2018, 1 (1), 79-89.

18. Fu, Y.; Li, X.; Chen, H.; Wang, Z.; Yang, W.; Zhang, H., CXC Chemokine Receptor 4 Antagonist Functionalized Renal Clearable Manganese-Doped Iron Oxide Nanoparticles for Active-Tumor-Targeting Magnetic Resonance Imaging-Guided BioPhotothermal Therapy. ACS Applied Bio Materials 2019, 2 (8), 3613-3621.

19. García-Soriano, D.; Amaro, R.; Lafuente-Gómez, N.; Milán-Rois, P.; Somoza, Á.; Navío, C.; Herranz, F.; Gutiérrez, L.; Salas, G., The influence of cation incorporation and leaching in the properties of Mn-doped nanoparticles for biomedical applications. Journal of Colloid and Interface Science 2020, 578, 510-521.

20. Pellico, J.; Lechuga-Vieco, A. V.; Almarza, E.; Hidalgo, A.; Mesa-Nuñez, C.; Fernández-Barahona, I.; Quintana, J. A.; Bueren, J.; Enríquez, J. A.; Ruiz-Cabello, J.; Herranz, F., In vivo imaging of lung inflammation with neutrophil-specific 68Ga nanoradiotracer. Scientific Reports 2017, 7 (1), 13242.

21. Colombo, M.; Carregal-Romero, S.; Casula, M. F.; Gutierrez, L.; Morales, M. P.; Bohm, I. B.; Heverhagen, J. T.; Prosperi, D.; Parak, W. J., Biological applications of magnetic nanoparticles. Chem Soc Rev 2012, 41 (11), 4306-34.

22. Gavilán, H.; Sánchez, E. H.; Brollo, M. E. F.; Asín, L.; Moerner, K. K.; Frandsen, C.; Lázaro, F. J.; Serna, C. J.; Veintemillas-Verdaguer, S.; Morales, M. P.; Gutiérrez, L., Formation Mechanism of Maghemite Nanoflowers Synthesized by a Polyol-Mediated Process. ACS Omega 2017, 2 (10), 7172-7184.

23. Caruntu, D.; Caruntu, G.; Chen, Y.; O'Connor, C. J.; Goloverda, G.; Kolesnichenko, V. L., Synthesis of Variable-Sized Nanocrystals of Fe3O4 with High Surface Reactivity. Chemistry of Materials 2004, 16 (25), 5527-5534. 
24. Hu, X.; Yu, J. C.; Gong, J.; Li, Q.; Li, G., $\alpha$-Fe2O3 Nanorings Prepared by a Microwave-Assisted Hydrothermal Process and Their Sensing Properties. Advanced Materials 2007, 19 (17), 2324-2329.

25. Carenza, E.; Barceló, V.; Morancho, A.; Montaner, J.; Rosell, A.; Roig, A., Rapid synthesis of water-dispersible superparamagnetic iron oxide nanoparticles by a microwave-assisted route for safe labeling of endothelial progenitor cells. Acta Biomaterialia 2014, 10 (8), 3775-3785.

26. Pellico, J.; Ruiz-Cabello, J.; Fernández-Barahona, I.; Gutiérrez, L.; LechugaVieco, A. V.; Enríquez, J. A.; Morales, M. P.; Herranz, F., One-Step Fast Synthesis of Nanoparticles for MRI: Coating Chemistry as the Key Variable Determining Positive or Negative Contrast. Langmuir 2017, 33 (39), 10239-10247.

27. Pellico, J.; Ruiz-Cabello, J.; Saiz-Alía, M.; Rosario, G.; Caja, S.; Montoya, M.; Fernández de Manuel, L.; Morales, M. P.; Gutiérrez, L.; Galiana, B.; Enríquez, J. A.; Herranz, F., Fast synthesis and bioconjugation of 68Ga core-doped extremely small iron oxide nanoparticles for PET/MR imaging. Contrast Media \& Molecular Imaging 2016, 11 (3), 203-210.

28. Wiogo, H.; Lim, M.; Munroe, P.; Amal, R., Understanding the Formation of Iron Oxide Nanoparticles with Acicular Structure from Iron(III) Chloride and Hydrazine Monohydrate. Crystal Growth \& Design 2011, 11 (5), 1689-1696.

29. Szczerba, W.; Żukrowski, J.; Przybylski, M.; Sikora, M.; Safonova, O.; Shmeliov, A.; Nicolosi, V.; Schneider, M.; Granath, T.; Oppmann, M.; Straßer, M.; Mandel, K., Pushing up the magnetisation values for iron oxide nanoparticles via zinc doping: X-ray studies on the particle's sub-nano structure of different synthesis routes. Physical Chemistry Chemical Physics 2016, 18 (36), 25221-25229.

30. Baig, M. M.; Yousuf, M. A.; Agboola, P. O.; Khan, M. A.; Shakir, I.; Warsi, M. F., Optimization of different wet chemical routes and phase evolution studies of $\mathrm{MnFe} 2 \mathrm{O} 4$ nanoparticles. Ceramics International 2019, 45 (10), 12682-12690.

31. Jolivet, J.-P.; Chanéac, C.; Tronc, E., Iron oxide chemistry. From molecular clusters to extended solid networks. Chemical Communications 2004, (5), 481-483.

32. Lim, M.; Chiang, K.; Amal, R., Photochemical synthesis of chlorine gas from iron(III) and chloride solution. Journal of Photochemistry and Photobiology A: Chemistry 2006, 183 (1), 126-132.

33. Thanh, N. T. K.; Maclean, N.; Mahiddine, S., Mechanisms of Nucleation and Growth of Nanoparticles in Solution. Chemical Reviews 2014, 114 (15), 7610-7630.

34. Zhang, H.; Li, L.; Liu, X. L.; Jiao, J.; Ng, C.-T.; Yi, J. B.; Luo, Y. E.; Bay, B.H.; Zhao, L. Y.; Peng, M. L.; Gu, N.; Fan, H. M., Ultrasmall Ferrite Nanoparticles Synthesized via Dynamic Simultaneous Thermal Decomposition for High-Performance and Multifunctional T1 Magnetic Resonance Imaging Contrast Agent. ACS Nano 2017, 11 (4), 3614-3631.

35. Fernández-Barahona, I.; Gutiérrez, L.; Veintemillas-Verdaguer, S.; Pellico, J.; Morales, M. d. P.; Catala, M.; del Pozo, M. A.; Ruiz-Cabello, J.; Herranz, F., Cu-Doped Extremely Small Iron Oxide Nanoparticles with Large Longitudinal Relaxivity: OnePot Synthesis and in Vivo Targeted Molecular Imaging. ACS Omega 2019, 4 (2), 27192727.

36. Zyuzin, M. V.; Honold, T.; Carregal-Romero, S.; Kantner, K.; Karg, M.; Parak, W. J., Influence of Temperature on the Colloidal Stability of Polymer-Coated Gold Nanoparticles in Cell Culture Media. Small 2016, 12 (13), 1723-1731.

37. Dominguez-Medina, S.; Blankenburg, J.; Olson, J.; Landes, C. F.; Link, S., Adsorption of a Protein Mono layer via Hydrophobic Interactions Prevents Nanoparticle 
Aggregation under Harsh Environmental Conditions. Acs Sustainable Chemistry \& Engineering 2013, 1 (7), 833-842.

38. Abdelwahed, W.; Degobert, G.; Stainmesse, S.; Fessi, H., Freeze-drying of nanoparticles: formulation, process and storage considerations. Advanced drug delivery reviews 2006, 58 (15), 1688-713.

39. Cornell, R. M.; Schwertmann, H. C. U., The Iron Oxides: Structure, Properties, Reactions, Occurences and Uses, Second Edition. In The Iron Oxides: Structure, Properties, Reactions, Occurences and Uses, Second Edition, Wiley-VCH, Ed. WileyVCH: 2003; pp 1-551.

40. Li, D.; Yun, H.; Diroll, B. T.; Doan-Nguyen, V. V. T.; Kikkawa, J. M.; Murray, C. B., Synthesis and Size-Selective Precipitation of Monodisperse Nonstoichiometric MxFe3-xO4 ( $\mathrm{M}=\mathrm{Mn}, \mathrm{Co})$ Nanocrystals and Their DC and AC Magnetic Properties. Chemistry of Materials 2016, 28 (2), 480-489.

41. Gutiérrez, L.; Morales, M. P.; Lázaro, F. J., Prospects for magnetic nanoparticles in systemic administration: synthesis and quantitative detection. Physical Chemistry Chemical Physics 2014, 16 (10), 4456-4464.

42. López, A.; Gutiérrez, L.; Lázaro, F. J., The role of dipolar interaction in the quantitative determination of particulate magnetic carriers in biological tissues. Physics in medicine and biology 2007, 52 (16), 5043-56.

43. Roch, A.; Gillis, P.; Ouakssim, A.; Muller, R. N., Proton magnetic relaxation in superparamagnetic aqueous colloids: a new tool for the investigation of ferrite crystal anisotropy. Journal of Magnetism and Magnetic Materials 1999, 201 (1), 77-79.

44. Rohrer, M.; Bauer, H.; Mintorovitch, J.; Requardt, M.; Weinmann, H. J., Comparison of magnetic properties of MRI contrast media solutions at different magnetic field strengths. Investigative radiology 2005, 40 (11), 715-24.

45. Muz, B.; de la Puente, P.; Azab, F.; Azab, A. K., The role of hypoxia in cancer progression, angiogenesis, metastasis, and resistance to therapy. Hypoxia (Auckl) 2015, 3, 83-92.

46. Valdés-Solís, T.; Valle-Vigón, P.; Álvarez, S.; Marbán, G.; Fuertes, A. B., Manganese ferrite nanoparticles synthesized through a nanocasting route as a highly active Fenton catalyst. Catalysis Communications 2007, 8 (12), 2037-2042.

47. Ramankutty, C. G.; Sugunan, S., Surface properties and catalytic activity of ferrospinels of nickel, cobalt and copper, prepared by soft chemical methods. Applied Catalysis A: General 2001, 218 (1), 39-51.

48. $\quad$ Liang, X.; He, Z.; Zhong, Y.; Tan, W.; He, H.; Yuan, P.; Zhu, J.; Zhang, J., The effect of transition metal substitution on the catalytic activity of magnetite in heterogeneous Fenton reaction: In interfacial view. Colloids and Surfaces A: Physicochemical and Engineering Aspects 2013, 435, 28-35.

49. Costa, R. C. C.; Lelis, M. F. F.; Oliveira, L. C. A.; Fabris, J. D.; Ardisson, J. D.; Rios, R. R. V. A.; Silva, C. N.; Lago, R. M., Novel active heterogeneous Fenton system based on $\mathrm{Fe} 3-\mathrm{xMxO} 4(\mathrm{Fe}, \mathrm{Co}, \mathrm{Mn}, \mathrm{Ni}$ ): The role of $\mathrm{M} 2+$ species on the reactivity towards H2O2 reactions. Journal of Hazardous Materials 2006, 129 (1), 171-178.

50. Costa, R. C. C.; Lelis, M. d. F. F.; Oliveira, L. C. A.; Fabris, J. D.; Ardisson, J. D.; Rios, R. R. V. A.; Silva, C. N.; Lago, R. M., Remarkable effect of Co and Mn on the activity of $\mathrm{Fe} 3-\mathrm{xMxO} 4$ promoted oxidation of organic contaminants in aqueous medium with $\mathrm{H} 2 \mathrm{O} 2$. Catalysis Communications 2003, 4 (10), 525-529.

51. Oliveira, L. C. A.; Fabris, J. D.; Rios, R. R. V. A.; Mussel, W. N.; Lago, R. M., Fe3-xMnxO4 catalysts: phase transformations and carbon monoxide oxidation. Applied Catalysis A: General 2004, 259 (2), 253-259. 
52. Yang, B.; Ding, L.; Yao, H.; Chen, Y.; Shi, J., A Metal-Organic Framework (MOF) Fenton Nanoagent-Enabled Nanocatalytic Cancer Therapy in Synergy with Autophagy Inhibition. Advanced Materials 2020, n/a (n/a), 1907152.

53. Feng, Q.; Liu, Y.; Huang, J.; Chen, K.; Huang, J.; Xiao, K., Uptake, distribution, clearance, and toxicity of iron oxide nanoparticles with different sizes and coatings. Scientific Reports 2018, 8 (1), 2082.

54. Di Corato, R.; Gazeau, F.; Le Visage, C.; Fayol, D.; Levitz, P.; Lux, F.; Letourneur, D.; Luciani, N.; Tillement, O.; Wilhelm, C., High-Resolution Cellular MRI: Gadolinium and Iron Oxide Nanoparticles for in-Depth Dual-Cell Imaging of Engineered Tissue Constructs. ACS Nano 2013, 7 (9), 7500-7512.

55. Wang, L.; Huang, J.; Chen, H.; Wu, H.; Xu, Y.; Li, Y.; Yi, H.; Wang, Y. A.; Yang, L.; Mao, H., Exerting Enhanced Permeability and Retention Effect Driven Delivery by Ultrafine Iron Oxide Nanoparticles with T1-T2 Switchable Magnetic Resonance Imaging Contrast. ACS Nano 2017, 11 (5), 4582-4592.

56. Van de Walle, A.; Kolosnjaj-Tabi, J.; Lalatonne, Y.; Wilhelm, C., EverEvolving Identity of Magnetic Nanoparticles within Human Cells: The Interplay of Endosomal Confinement, Degradation, Storage, and Neocrystallization. Accounts of Chemical Research 2020.

57. Phelps, M. E., Positron emission tomography provides molecular imaging of biological processes. Proc Natl Acad Sci U S A 2000, 97 (16), 9226-9233.

58. Alexis, F.; Pridgen, E.; Molnar, L. K.; Farokhzad, O. C., Factors affecting the clearance and biodistribution of polymeric nanoparticles. Mol Pharm 2008, 5 (4), 505515. 